Research Article

\title{
The Experimental Studies on Behavior of Ultrahigh-Performance Concrete Confined by Hybrid Fiber-Reinforced Polymer Tubes
}

\author{
Zong-cai Deng and Jiu-ling Qu \\ College of Architecture and Civil Engineering, Beijing University of Technology, Beijing 100124, China \\ Correspondence should be addressed to Zong-cai Deng; dengzc@bjut.edu.cn
}

Received 19 October 2014; Revised 23 February 2015; Accepted 23 February 2015

Academic Editor: Dachamir Hotza

Copyright (C) 2015 Z.-c. Deng and J.-1. Qu. This is an open access article distributed under the Creative Commons Attribution License, which permits unrestricted use, distribution, and reproduction in any medium, provided the original work is properly cited.

\begin{abstract}
This paper conducts axial compression test of ultrahigh performance concrete- (UHPC-) filled hybrid FRP (HFRP) tubes, using the alternating hybrid technology to improve the deformation capacity of FRP tube and measure the axial compressive responses of ultimate strength, strains, and stress-strain curve of confined specimens. The test results show that the local rupture of HFRP tubes did not lead to explosive failure of UHPC cylinder, and its ductility is better than that of UHPC confined by only one type of FRP tube; HFRP tube can effectively improve the compressive strength and ultimate strain of UHPC specimens; the stress-strain curves divide into three distinct regions: linear phase, transition phase, and linear strengthening phase. None of the models provided a reasonable prediction for strength and strain of HFRP-confined UHPC specimen; therefore, a new ultimate strength and strain perdition model considering the confinement effectiveness of different hybrid FRP series was proposed. The new proposed model presented the best fitting results. The stress-strain responses predicted by the existing models are all below the experimental curves; therefore, a new three-stage constitutive model was proposed, which relatively fits the test curves better than the existing models.
\end{abstract}

\section{Introduction}

Lateral confinement can significantly improve the strength, ductility, shear capacity, and seismic performance of concrete columns [1]. Studies on the deformation characteristics and the constitutive model of confined concrete are the basis of the structural design and nonlinear analysis. The study's results can be used to determine the amount of lateral confinement for reinforce concrete (RC) columns or piers in seismic areas and offer valuable reference for future studies and applications.

FRP has a high strength to weight ratio, stiffness to weight ratio, and good corrosion resistance performance. Recently Ozbakkaloglu [2,3] revealed that over 200 experimental studies have been conducted over the last two decades on the compressive behavior of FRP-confined concrete, resulting in the developments of over 80 axial stress-strain models
[4-7]. The majority of these studies reported on FRPwrapped specimens, and relatively few studies focused on the behavior of concrete-filled FRP tubes (CFFTs) [8-11]. In early studies of FRP confinement, the models for steel-confined concrete were directly applied to describe the stress-strain behavior of FRP-confined concrete. Hence, the stress-strain curve given by these early models is a parabolic curve. The bilinear stress-strain curves models are used more frequently in the subsequent studies for FRP-confined concrete. And most models for FRP-confined normal concrete describe the stress-strain curve as follows: the initial ascending portion is parabola, which was followed by a second region that was approximately linear. Toutanji [12] modified Ahmad and Khaloo's model [13] for FRP-confined concrete, which used the slopes of the initial ascending branch and the postpeak second branch to describe the stress-strain curve. Hognestad's parabola [14] and four-parameter models [15-17] 
have been used for describing the initial ascending parabola. Among the 80 axial stress-strain models, the most commonly used stress-strain models are the ones presented by Samaan et al. [18], Toutanji [12], Lam and Teng [19], and Saadatmanesh et al. [20], which are applicable to FRP-confined concrete.

Currently a few studies research the confinement model of high strength concrete (HSC) with FRP. Lim and Ozbakkaloglu report a large experimental test database on a study about the axial compressive behavior of FRP-confined HSC [21], which consists of 237 axial compression tests results for FRP-confined HSC. The study revealed that the availability of the existing FRP-confined normal concrete models applicable to FRP-confined HSC is extremely limited, and many existing stress-strain models developed for FRP-confined concrete assessed by using the HSC database do not perform well. Out of the 88 confined models developed for FRP-confined concrete, only six models were directly applicable to FRPconfined HSC (Miyauchi et al. [22]; Mandal et al. [23]; Berthet et al. [24]; Cui and Sheikh [25]; Xiao et al. [26]; Pham and Hadi [27]).

UHPC, as a new cement based material, has been rapidly developed and utilized especially in bridges and structures recently [28]. Compared to the conventional and high strength concrete, the following advantages of mechanical properties of UHPC have been proved: ultrahigh compressive strength, high tensile strength, ductility, and durability. Furthermore, the higher shear resistance of UHPC can reduce the need for transverse and shear reinforcement. Multiple cracks characteristics, high strength, high toughness fracture energy, deformation capacity, and especially resistance, make UHPC an important material for structural applications in seismic regions. UHPC reinforced with steel fiber has larger dilation deformation capacity than that of HSC and has better confinement effects. Fischer et al. [29] studied the performance of reinforced UHPC columns under cyclic lateral loads. The test results show that the ductile behavior of UHPC allows for high deformation of steel reinforcement. In another study, Billington and Yoon showed that the higher energy dissipation and damage tolerance may be achieved up to a drift ratio of $3 \% \sim 6 \%$ in bridge piers with UHPC within their plastic hinge regions [30]. Despite a decade of studies on UHPC, little is known about its confinement behavior. Zohrevand and Mirmiran conducted an axial compression test of UHPC confined with CFRP and GFRP tubes and measured the deformation capacity and strength of specimens [31]. They found that stress-strain curve of FRP confined UHPC is a bilinear curve, which contain a linear initial ascending portion, after that a nolinear transition segment, and then a hardening segment which was approximately linear. They then compared the test results with predicted values using the existing models and found that the existing models show relatively large errors on the stress-strain curves, strength, and deformation. Cyclic behaviors of hybrid columns made of UHPC and FRP were studied by Zohrevand and Mirmiran [32]. The results indicated that the ductility of this hybrid column increases with FRP rupture strain, and FRP tube-confined UHPC column without any internal reinforcement achieves the same flexural strength and ductility as its steel-reinforced counterpart. FRP tube-confined UHPC specimens showed significantly higher flexural strength and initial stiffness and lower residual drift as compared with RC specimen. This hybrid system can be optimized for strength and ductility as a viable alternative to the conventional RC column.

The stress-strain curve for FRP-confined UHPC is divided into three stages: a linear initial ascending segment, a parabolic transition segment, and a linear hardening segment. The initial ascending branch of FRP-confined UHPC is significantly different from normal concrete. The initial ascending region of confined normal concrete is parabolic but approximately linear for FRP-confined UHPC. Fourparameter Teng and Toutanji models, developed for FRPconfined normal concrete, are not applicable to FRP-confined UHPC. So, it is necessary to develop a stress-strain model for FRP-confined UHPC based on the test results.

Moreover, most of the studies on confinement behavior and axial compressive strength and deformation capacity model only involve one kind of conventional FRP. So far, three common FRP composites of carbon FRP (CFRP), aramid FRP (AFRP), and glass FRP (GFRP) are single used for confining concrete columns. One type of FRP composite has a linear elastic stress-strain response with brittle rupture failure at a small rupture strain [33]. If one type of FRP was used for confining concrete, the strength and ultimate strain can be improved, but the FRP jacket ruptures abruptly at ultimate hoop tensile strain, and the fracture section of FRP jacket is straight, because the large elastic energy absorbed during loading is dissipated quickly at rupture strain. Given this background, a new category hybrid FRP composite has recently been used as an alternative structural application to conventional FRP in seismic areas. Hybrid FRP compositesconfined UHPC can improve the ductility and strength, and HFRP jacket ruptures at a multiple stage and the absorbed elastic energy do not dissipate quickly. Confining UHPC with HFRP tubes is an alternative manner because of the efficient combination of two high strength materials to form a high-performance member that benefits from a substantial increase in ductility compared with unconfined UHPC members. So far characteristics of UHPC-filled HFRP tubes under axial compression have not been reported yet. The present study has three specific objectives: (1) to develop a good understanding of the compressive stress-strain behavior of UHPC confined with HFRP; (2) to examine whether existing confinement models developed for conventional FRPs and concrete are applicable to HFRP-confined UHPC; and (3) to develop a new stress-strain relationship for HFRP tubesconfined UHPC based on the test results.

\section{Experimental Program}

2.1. Specimen Fabrication. A total of four types of unidirectional fiber sheets are used in this test: carbon fiber sheets, aramid fibers sheets, basalt fiber sheets, and glass fiber sheets. The mechanical properties of the fiber sheets are shown in Table 1, and the tensile properties of HFRP laminate with epoxy are shown in Table 2. A PVC tube of height $200 \mathrm{~mm}$ and diameter $100 \mathrm{~mm}$ (length to diameter ratio $L / D=2$ ) 
TABLE 1: Mechanical properties of fiber sheet.

\begin{tabular}{lcccc}
\hline Type of fiber sheet & Tensile strength (MPa) & Longitudinal tensile modulus (GPa) & Elongation (\%) & Thickness (mm) \\
\hline Carbon fiber sheet & 3400 & 240 & 1.42 & 1.60 \\
Aramid fibers sheet & 2000 & 125 & 3.45 & 0.167 \\
Basalt fiber sheet & 3103 & 90 & 3.27 & 0.339 \\
Glass fiber sheet & 1800 & 55 & 0.436 \\
\hline
\end{tabular}

TABLE 2: Mechanical properties of HFRP laminate with epoxy.

\begin{tabular}{lcccc}
\hline Type of HFRP laminate with epoxy & Thickness $(\mathrm{mm})$ & Longitudinal tensile modulus $(\mathrm{GPa})$ & Elongation $(\%)$ & Tensile strength $(\mathrm{MPa})$ \\
\hline A1B1 & 0.532 & 23.9 & 4.5 & 1078.8 \\
B1G1 & 0.775 & 18.4 & 4.7 & 863.1 \\
C1B1 & 0.506 & 43.7 & 39.7 & 1044.9 \\
C1G1 & 0.603 & 31.1 & 2.5 & 1066.6 \\
C2A1G1 & 0.963 & 33.7 & 3.2 & 979.8 \\
C2A2G2 & 1.592 & 27.5 & 3.0 & 1010.1 \\
C2B1G1 & 1.109 & 30.3 & 2.9 & 790.8 \\
C2B2G2 & 1.884 & 2.7 & 823.2 \\
\hline
\end{tabular}

is prepared. Clean the surface of the PVC tube, grind the sharp edges, and cut fabric sheets to appropriate length for each layer of wraps, with a minimum overlap of $100 \mathrm{~mm}$. Mix the two epoxy components for 5 mins and then use a brush and a roller to make the fabric fully saturated with epoxy. Wrap fabric sheets around the tube according to the requirement as designed for specimens, and then apply additional epoxy as an overcoat to ensure enough wetting of the fabric. Lastly wrap both ends of the specimen near loading point with $30 \mathrm{~mm}$ wide carbon fiber sheets reinforced polymer to prevent premature damage at this area during loading. After 21 days, the PVC tubes were removed and the bottoms of all HFRP tubes were plugged using plastic caps, allowing them to be used as molds. HFRP tube is not used for confining the core concrete and also used as work-form here. The UHPC was poured into the HFRP tubes, as shown in Figure 1. All specimens were curried in standard curing room. After 28 days, the top and bottom surface of each specimen were grinded smooth for the compression tests.

In this study, superfine cement was used to prepare the UHPC without silica fume. The steel fibers had a length of $8 \mathrm{~mm}$, diameter of $0.12 \mathrm{~mm}$, and a tensile strength of $2800 \mathrm{MPa}$. The UHPC proportions are presented in Table 3.

2.2. Specimen Labeling. Three cylindrical specimens are prepared for each group of UHPC-filled HFRP tubes specimens. The specimens' labels are listed in Table 4, where letters of the specimen label represent the type of fiber-reinforced polymer; and the number after the letter represents number of layers of that type of fiber sheets. For example, C2G2 indicates that the specimens are wrapped with two layers of carbon fiber sheets and two layers of glass fiber sheets.

2.3. Specimens Loading. Attach two lateral and two longitudinal strain gauges on the middle surface of the HFRP tubes. All specimens were tested under uniaxial compression using a $4,000 \mathrm{kN}$ universal testing machine with external pressure sensor and displacement meter. Data acquisition system is used to obtain and record the lateral and longitudinal strain and the axial stress during the loading process (Figure 2 ). The loading rate is $110 \mathrm{kN} / \mathrm{min}$.

\section{Test Results and Failure Mechanisms}

3.1. Specimen Failure Process. The failure process of unconfined UHPC specimens is as follows: initial loading, hoop deformation of the specimens is small, while UHPC is in elastic stage; when loading reaches $0.3 N_{u}\left(N_{u}\right.$ is ultimate load), longitudinal cracks begin to appear on the surface of specimens, and crack growth rate accelerates along with load; when loading reaches $0.75 N_{u}$, longitudinal cracks extend to two ends of specimen, the midheight section of specimen gradually expands outward, and hoop deformation increases; when loaded to $N_{u}$, the vertical or diagonal cracks extend throughout the specimen, and they exhibit brittle failure characteristics, but the specimens maintain good integrity.

The damage process of UHPC confined by HFRP tube is as follows: at initial stage of loading, the radial deformation of HFRP tube is small; therefore, the confining effect of HFRP tube is insignificant. As load increases, the core concrete begins to expand laterally, and the confinement effect of HFRP tube is gradually activated, and colloid "flap" sound can be heard at the moment. When the load is about $0.9 N_{u}$, a transverse crack forms on the HFRP tube, which is followed by sounds of fracturing HFRP and outward bulging of the specimen's midheight section. When load reaches $N_{u}$, the midheight section of the HFRP tube cracks and then the cracks propagate towards both ends of the specimen. The failure was accompanied with a very limited noise, unlike the explosive process observed in one type of conventional FRP-confined UHPC cylinders. In general, in these HFRPconfined UHPC cylinders, the local rupture of FRP tubes did not lead to an explosive failure of the UHPC cylinder, unlike with single conventional FRP-confined specimens. 
TABLE 3: Ultrahigh-performance concrete mix proportion in $\mathrm{kg}$ per $\mathrm{m}^{3}$.

\begin{tabular}{lccccccc}
\hline Microfine cement & Portland cement & Blast furnace slag & Quartz sand & Steel fiber & Water & Water reducing agents & Defoaming agent \\
\hline 237.5 & 474.0 & 474.0 & 1076.9 & 78.5 & 237.5 & 14.2 & 0.7 \\
\hline
\end{tabular}

TABLE 4: Summary of test results.

\begin{tabular}{|c|c|c|c|c|c|c|c|c|}
\hline $\begin{array}{l}\text { Specimen } \\
\text { group }\end{array}$ & $\begin{array}{c}f_{l} \\
(\mathrm{MPa})\end{array}$ & $\begin{array}{c}E_{l} \\
(\mathrm{MPa})\end{array}$ & $\begin{array}{l}\text { Confinement ratio } \\
\qquad f_{l} / f_{c o}^{\prime}\end{array}$ & $\begin{array}{l}\text { Ultimate } \\
\text { strength }(\mathrm{MPa})\end{array}$ & $\begin{array}{c}\text { Ultimate } \\
\text { axial strain } \\
(\mu \varepsilon)\end{array}$ & $\begin{array}{l}\text { Ultimate hoop } \\
\text { strain }(\mu \varepsilon)\end{array}$ & $\begin{array}{l}\text { Confinement effectiveness } \\
\qquad f_{c c}^{\prime} / f_{c o}^{\prime}\end{array}$ & $\begin{array}{l}\text { Axial strain } \\
\text { ratio } \varepsilon_{c c} / \varepsilon_{c o}\end{array}$ \\
\hline $\mathrm{P} 0$ & N/A & N/A & N/A & 82.8 & 3080 & 829 & $\mathrm{~N} / \mathrm{A}$ & N/A \\
\hline $\mathrm{A} 1 \mathrm{~B} 1$ & 11.48 & 253.84 & 0.13 & 130.4 & 12750 & 8960 & 1.57 & 4.76 \\
\hline $\mathrm{A} 2 \mathrm{~B} 2$ & 22.95 & 507.68 & 0.26 & 168.0 & 18050 & 14730 & 2.03 & 6.74 \\
\hline A3B3 & 34.43 & 761.52 & 0.39 & 208.1 & 19680 & 15070 & 2.51 & 7.34 \\
\hline B1G1 & 13.38 & 285.59 & 0.16 & 122.8 & 11090 & 7760 & 1.48 & 4.14 \\
\hline B2G2 & 26.76 & 571.18 & 0.32 & 165.2 & 16690 & 10570 & 2.00 & 6.23 \\
\hline B3G3 & 40.14 & 856.77 & 0.48 & 204.1 & 18920 & 11920 & 2.46 & 7.06 \\
\hline C1B1 & 10.17 & 442.64 & 0.12 & 110.7 & 8690 & 5250 & 1.34 & 3.24 \\
\hline $\mathrm{C} 2 \mathrm{~B} 2$ & 20.34 & 885.28 & 0.25 & 162.4 & 10440 & 6870 & 1.96 & 3.90 \\
\hline C3B3 & 30.51 & 1327.92 & 0.37 & 213.2 & 12850 & 8980 & 2.57 & 4.79 \\
\hline C1G1 & 12.14 & 478.66 & 0.15 & 154.0 & 10120 & 7190 & 1.86 & 3.78 \\
\hline $\mathrm{C} 2 \mathrm{G} 2$ & 24.28 & 957.32 & 0.29 & 192.2 & 14650 & 10820 & 2.32 & 5.47 \\
\hline C3G3 & 36.42 & 1435.98 & 0.44 & 260.2 & 18940 & 12460 & 3.14 & 7.07 \\
\hline $\mathrm{C} 2 \mathrm{AG}$ & 18.87 & 598.67 & 0.23 & 128.6 & 10330 & 6900 & 1.55 & 3.85 \\
\hline $\mathrm{C} 2 \mathrm{~A} 2 \mathrm{G} 2$ & 32.16 & 1073.08 & 0.38 & 201.7 & 16080 & 11160 & 2.44 & 6.00 \\
\hline C2BG & 17.54 & 609.12 & 0.21 & 139.5 & 10450 & 6310 & 1.68 & 3.90 \\
\hline $\mathrm{C} 2 \mathrm{~B} 2 \mathrm{G} 2$ & 31.02 & 1143.54 & 0.37 & 195.3 & 14960 & 10670 & 2.36 & 5.58 \\
\hline
\end{tabular}

The failure process of HFRP-confined specimens is longer, and HFRP tubes rupture process in multiple stages. The absorbed energy during loading does not dissipate quickly at ultimate hoop tensile strain. This multiple failure process and deformability of specimens make HFRP-confined UHPC columns a promising structural application in seismic regions.

3.2. Analysis of Failure Modes and Mechanism. The typical failure mode of unconfined specimens is as shown in Figures 3(a) 3(d). Vertical cracks and diagonal microcracks appear on the surface of specimens and divide the specimen into independent parts. Some fragments of concrete disintegrated from the specimen. Steel fibers at the cracking plane pull out but the specimen retains its complete form at the end of the test.

Failure mechanism of unconfined specimens is as follows: during compression of the specimens, longitudinal cracks first appear at the midheight section due to lateral expansion of UHPC, as seen in Figure 4(a). On the other hand, the two ends of the specimen are subjected to lateral confinement due to the friction force arising from the steel plates at the loading ends, which limits the lateral expansion of the end regions of the specimen, as shown in Figure 4(b). The effect of the lateral confinement caused by the loading steel plates reduces with increase in distance from the loading ends. Longitudinal strains on the specimen side surface are compressive, while hoop strain is in tensile state, as shown in Figure 4(c). Longitudinal cracks on the midheight surface of the specimen extend rapidly to both ends, and diagonal cracks may appear as seen in Figure 4(d).

The confinement mechanism of UHPC-filled HFRP tubes is as shown in Figures 5(a) 5(c).

The bonding between HFRP tube surface and UHPC is good during axial compression; thus bond slip does not occur. And the lateral strain of HFRP tube and the radial strain of the UHPC are consistent. Therefore, the equation for calculating the lateral confinement strength $f_{l}$ of HFRP and lateral confinement stiffness $E_{l}$ can be derived from the force balance principle of cross section as given below:

$$
\begin{aligned}
f_{l} & =\frac{2 f_{f} t}{D}, \\
E_{l} & =\frac{2 E_{f} t}{D},
\end{aligned}
$$

where $f_{f}, E_{f}$, and $t$ are the actual hoop rupture strength, the elasticity modulus, and the thickness of HFRP laminate with epoxy, respectively; $D$ is the internal diameter of HFRP tube.

The confinement mechanism of UHPC-filled HFRP tubes is as follows: HFRP tube plays a passive confinement role after UHPC undergoes lateral expansion as seen in Figures 5(a) 5(b). At the initial loading stage, the confined stress of HFRP tube on core concrete is very small. When loading begins to 


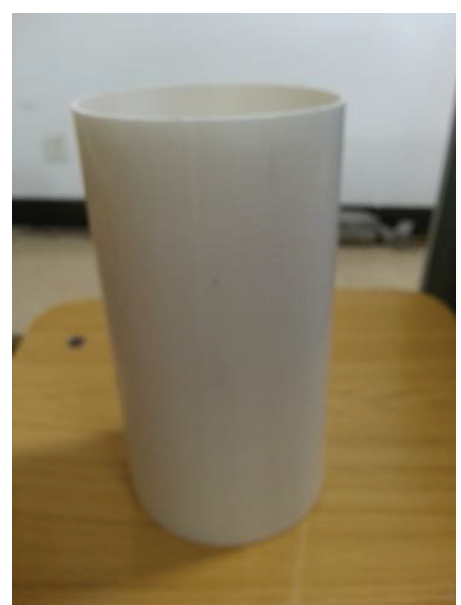

(a) PVC tubes

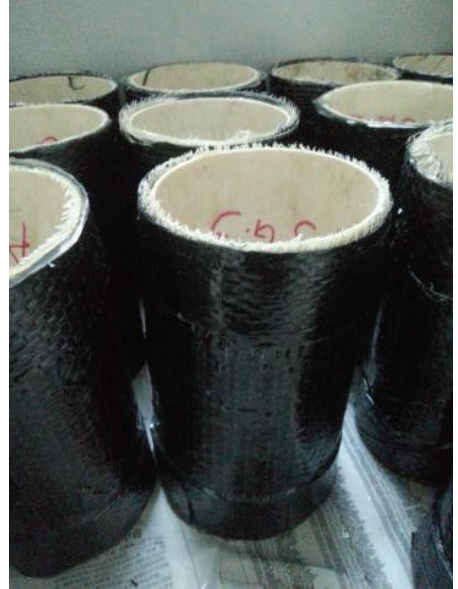

(b) HRFP tubes

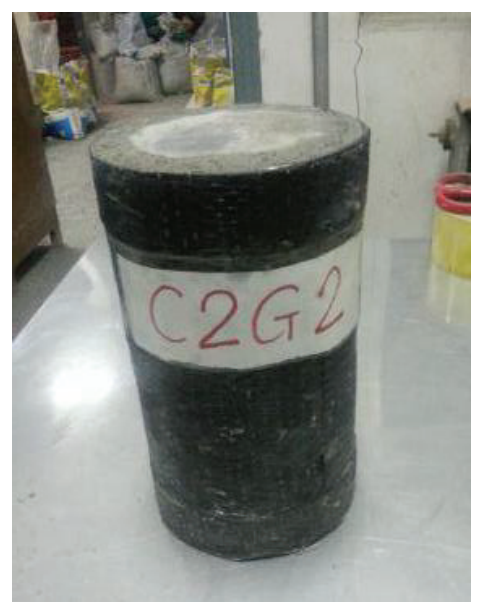

(c) UHPC-filled HFRP tubes

FIgURe 1: Preparation of UHPC-filled HFRP tubes.
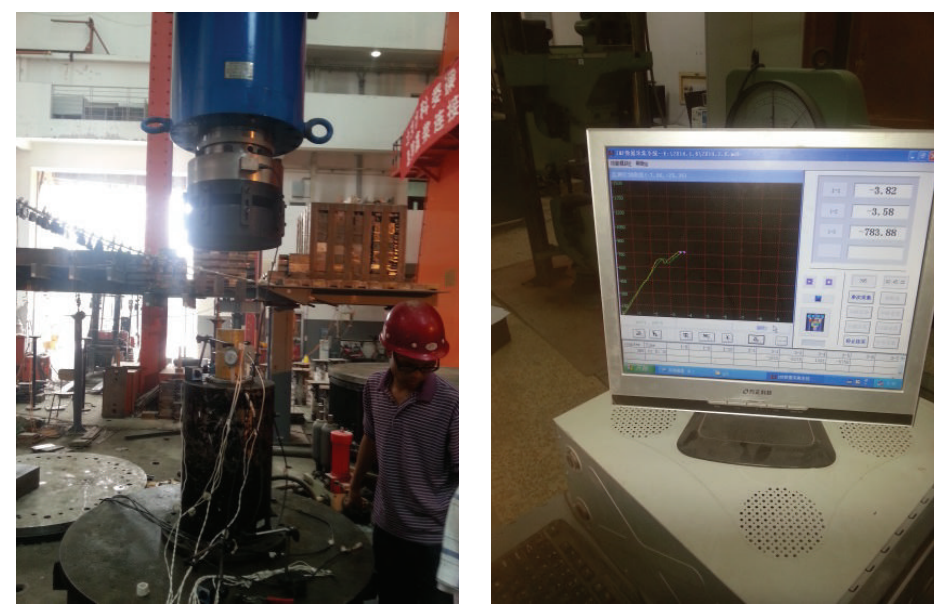

FIGURE 2: Test setup and data acquisition system.

approach the compressive strength $f_{c o}^{\prime}$ of unconfined UHPC, cracks form and develop, and lateral expansion deformation of UHPC increases rapidly. At this stage the confinement effect of HFRP tube is gradually activated and thus causes the core concrete to be subjected to triaxial compression state, which contributes to enhancing strength and deformation capacity of specimens, as seen in Figure 5(c).

When the hoop strain of HFRP tubes almost reaches its ultimate tensile strain, the hybrid fibers did not lead to an explosive failure, but failed in multiple stages model as losing confinement capacity gradually. The failure modes of UHPCfilled HFRP tubes are shown in Figures 6(a) 6(c).

There are mainly three typical failure modes of UHPCfilled HFRP tubes.

(i) When HFRP plate has relatively small $E_{l}$ and exhibits step by step failure characteristics in tensile test, which results from the hybrid effect, HFRP-confined specimen is likely to undergo ductile failure mode, as shown in Figure 6(a). The outermost layer of FRP undergoes tensile fracture firstly, while the inner layer is not completely fractured. Core concrete does not indicate any significant crashing since there are no fragments that fall off; therefore, the specimens still maintain a substantial load bearing capacity. This is the ideal failure mode which exhibits ductile failure characteristics.

(ii) When the $E_{l}$ of HFRP plate is medium and toughness of HFRP is relatively high during tensile, the confined specimens show a certain degree of ductility failure mode, as seen in Figure 6(b). The outermost fiber sheet fractured firstly and then was followed by the inner fiber and extended toward the two ends of specimen. Fragments of crushed UHPC can be observed in cracks, leading to loss of bearing capacity.

(iii) When the $E_{l}$ of HFRP plate is relatively large, the confined specimens may attain a brittle fracture failure mode, as seen in Figure 6(c). The inner and outer layers of FRP tube almost fracture simultaneously, the 


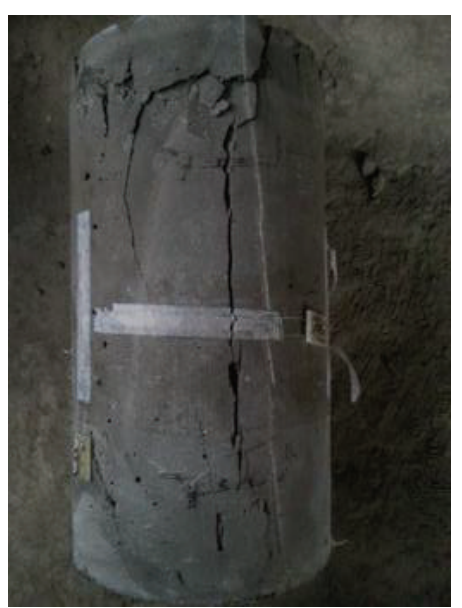

(a)

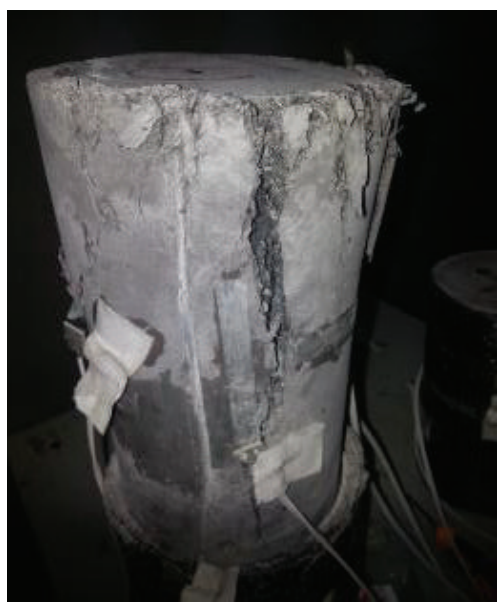

(b)

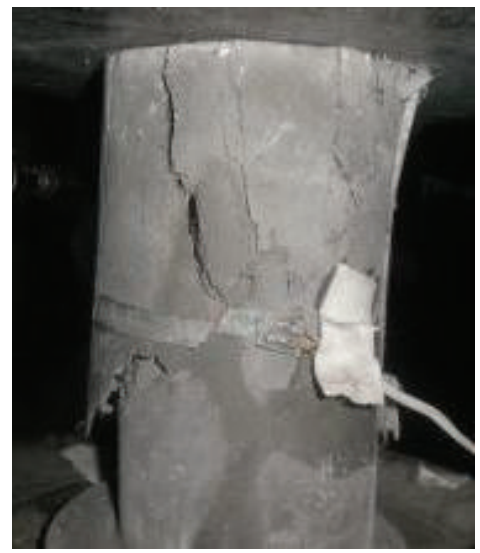

(d)

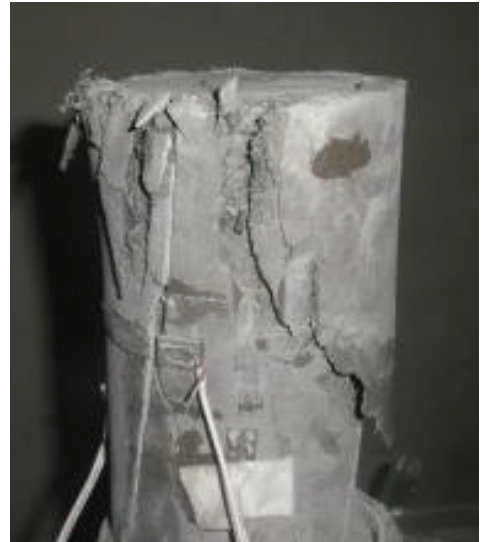

(c)

FIgURE 3: Typical failure mode of unconfined UHPC.

fractured cross section of HFRP is relatively smooth, and crushed UHPC is visible through the crack.

3.3. Test Results. The average of test results for each group of specimens is shown in Table 4 , where $f_{l} / f_{c o}^{\prime}$ is the confinement ratio, $f_{c c}^{\prime} / f_{c o}^{\prime}$ is the confinement effectiveness, $\varepsilon_{c c} / \varepsilon_{c o}$ is the axial strain ratio, $f_{c o}^{\prime}$ is the peak stress of unconfined UHPC specimens, $\varepsilon_{c o}$ is axial strain of unconfined UHPC specimens corresponding to $f_{c o}^{\prime}$ and $\varepsilon_{c o}=0.00268, f_{c c}^{\prime}$ is the peak stress of UHPC-filled HFRP tube specimen, and $\varepsilon_{c c}$ is the ultimate strain of HFRP-confined specimens.

3.4. Stress-Strain Curves. Figure 7 shows the measured stressstrain $(\sigma-\varepsilon)$ curve for unconfined UHPC specimens under axial compression. The $\sigma-\varepsilon$ curve of unconfined UHPC specimens is different from that of conventional concrete specimens, in the fact that the $\sigma-\varepsilon$ curve for unconfined UHPC specimens shows a nearly linear relationship at the ascending stage, while curves for conventional concrete display nonlinear relationship at the ascending stage.

Figure 8 shows the measured $\sigma-\varepsilon$ curve for UHPCfilled HFRP tubes under axial compression. The curves can be divided into three stages: initial linear stage, nonlinear transition stage, and linear hardening stage. At initial loading stage the $\sigma-\varepsilon$ curve is almost a straight line, which is similar to that of unconfined UHPC specimens, and the gradient at the ascending stage of the $\sigma-\varepsilon$ curves for different layers of fiber sheets and different types of hybrid FRPs-confined specimens is almost the same. The initial stiffness of all confined specimens shows no significant change, since the HFRP jacket's confinement effect is not yet activated; thus the initial stiffness of the confined and unconfined UHPC specimens is almost equal to about $(40 \pm 3) \mathrm{GPa}$. When the load approaches the strength of unconfined specimens, dilation deformation increases; thus the confinement effect of HFRP tube is activated, the $\sigma-\varepsilon$ curves begin to show nonlinear characteristics, and the specimen enters elasticplastic stage. At the final linear strengthening phase, the $\sigma-\varepsilon$ curve almost becomes a straight line, but its gradient is significantly less than the gradient at initial phase. This indicates that HFRP tube plays the full role of confinement for UHPC and thus effectively improves the strength and deformation capacity of specimens.

From Figure 8, it can be seen that when the axial stress has just exceeded $f_{c o}^{\prime}$, specimens wrapped by two layers 


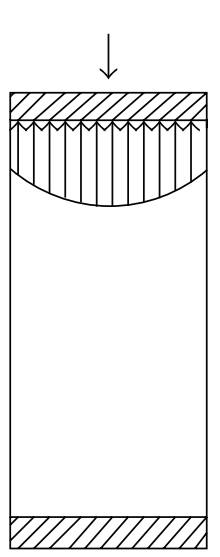

(a)

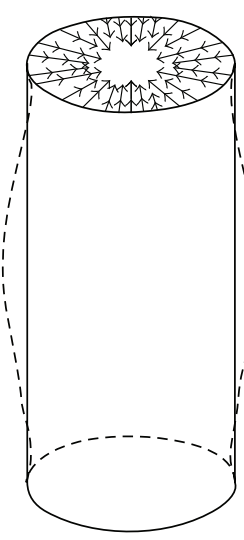

(b)

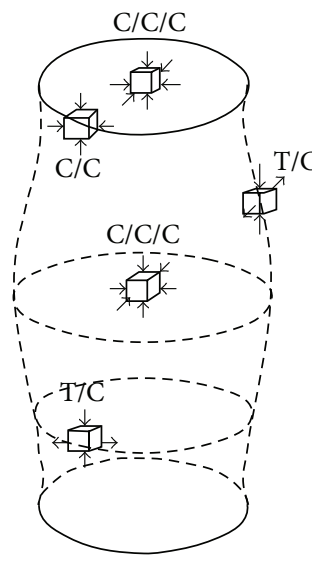

(c)

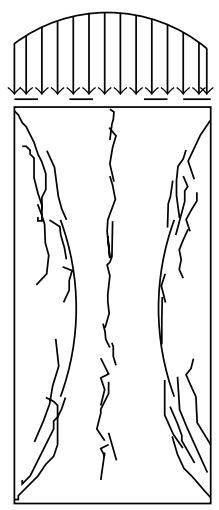

(d)

FIGURE 4: Typical failure mechanism of unconfined UHPC.

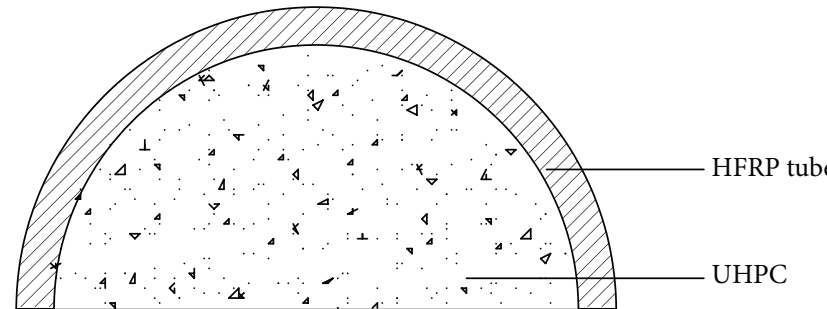

(a)

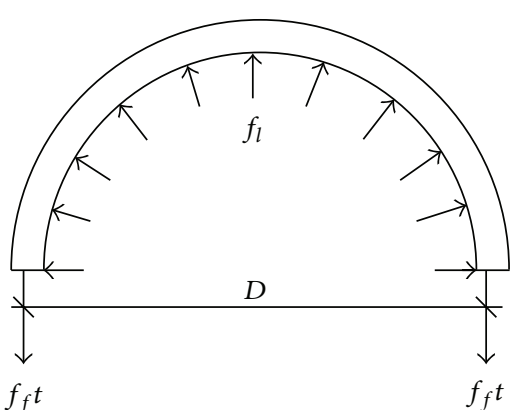

(b)

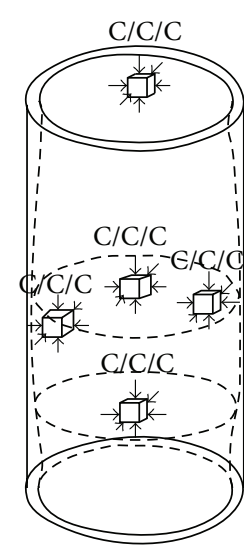

(c)

Figure 5: Confinement mechanism of UHPC-filled HFRP tubes.

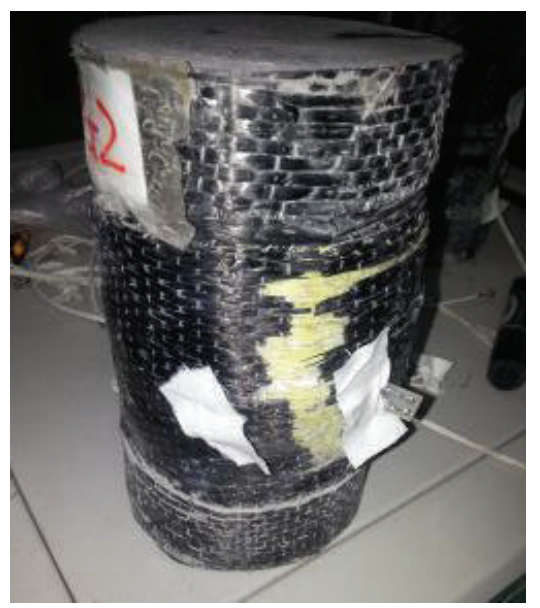

(a)

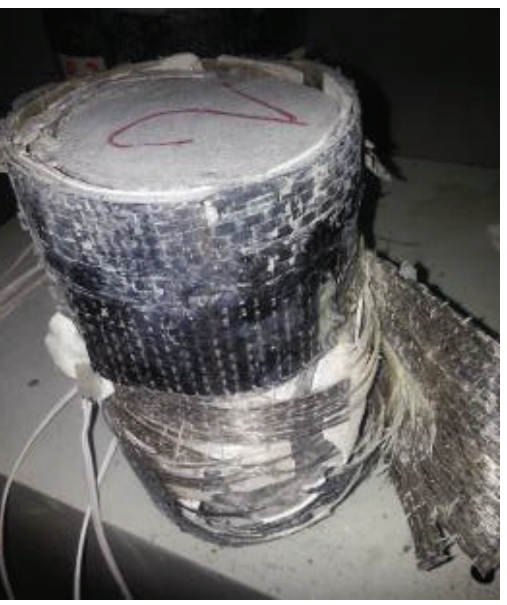

(b)

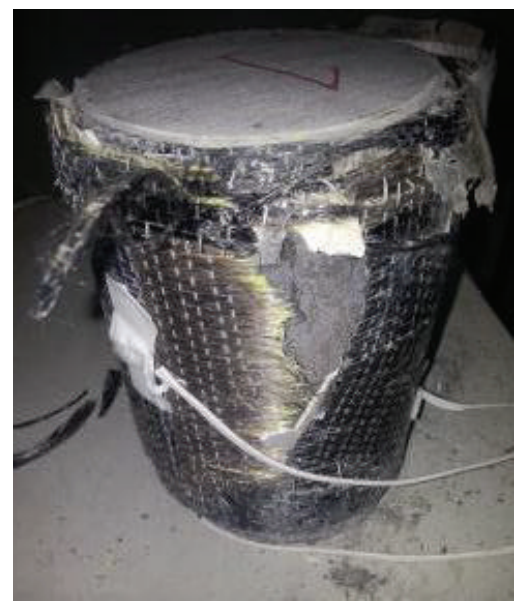

(c)

FIgURE 6: Typical failure modes of UHPC-filled HFRP tubes. 


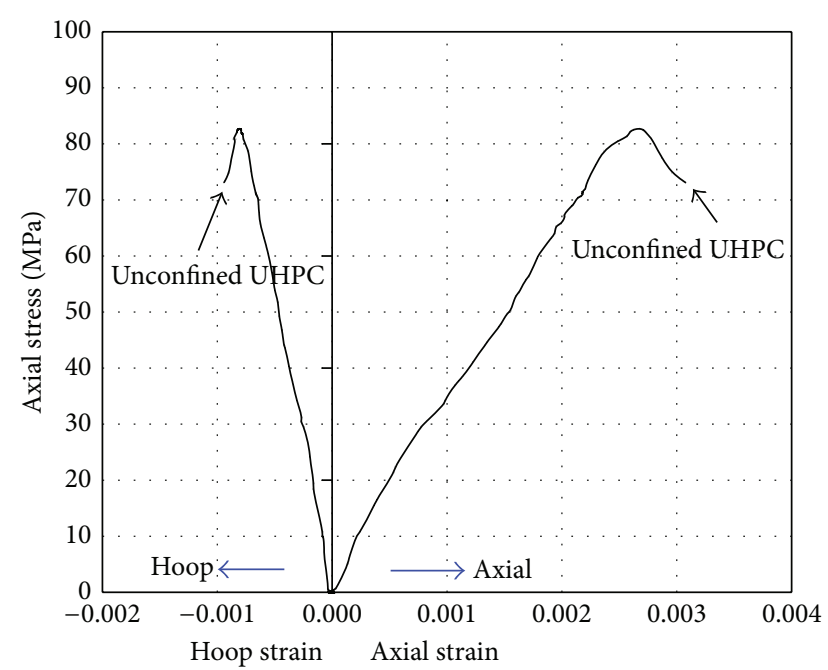

FIGURE 7: Average stress-strain response curves for unconfined UHPC (group P0 specimens).

of different fiber sheets (i.e., A1B1) begin to show stiffness degradation, while specimens wrapped by four- and six-layer sheets (i.e., A2B2, A3B3) can still maintain a relatively high stiffness. After that the $\sigma-\varepsilon$ curves of two-layer specimens ascend in a straight line with a small gradient, and there is rapid increase in both longitudinal and radial deformation with load. Meanwhile, the gradients of the $\sigma-\varepsilon$ curves of four- and six-layer specimens are larger and the deformation increases relatively slowly. Moreover, the $f_{c c}^{\prime}$ and $\varepsilon_{c c}$ values of four- and six-layer specimens are relatively larger than the ones of two-layer specimens.

3.5. Influential Factors. The main factors affecting the axial compression performance of UHPC confined by HFRP tube are number of layers of fiber sheets and type of hybrid fibers. Compared with unconfined UHPC specimens, UHPC-filled HFRP tube specimens show significant improvement of strength and deformation capacity. The degree of improvement strength and strain varies depending on the number of layers of fiber sheets and type of hybrid fiber, as shown in Figures 9(a) and 9(b). In those figures, C/GFRP represents a hybrid of carbon fiber with glass fiber sheets, while $\mathrm{C} / \mathrm{B} / \mathrm{GFRP}$ represents a hybrid of carbon fiber, basalt fiber, and glass fiber sheets. For instance C1G1, C2G2, and C3G3 specimens are referred to as C/GFRP hybrid series, and C2B1G1 and C2B2G2 specimens are C/B/GFRP hybrid series; the naming of the other series is done in the same way.

3.5.1. The Effects of Number of Layers of HFRP. From Figures 9(a) and 9(b), we see that the strength and deformation capacity of confined specimens increase with the number of fiber sheet layers. This is because increasing layers of fiber sheet increases the thickness of HFRP tube, thus enhancing the effectiveness of lateral confinement. With high confinement stress, the deformation capacity of UHPC increases, hence delaying the time before failure and thereby increasing the compressive strength and ultimate strain of confined specimen. For the same type of HFRP sheets, such as A1B1, $\mathrm{A} 2 \mathrm{~B} 2$, and $\mathrm{A} 3 \mathrm{~B} 3$ or $\mathrm{C} 2 \mathrm{~B} 1 \mathrm{G} 1$ and $\mathrm{C} 2 \mathrm{~B} 2 \mathrm{G} 2$, the relationship between number of HFRP layers and increment of strength is almost a linear relationship as seen in Figure 9(a). In the case of C/GFRP specimen series, when the layers of fiber sheets are more than 4 , the strength confinement efficiency increases significantly. Figure 9(b) shows that deformation capacity of the C/GFRP series specimens increases almost linearly with fiber sheet layers. For the B/GFRP and A/BFRP series specimens, when the number of sheet layers is more than 4 , the rate of increase in deformation capacity of the specimen decreases.

3.5.2. The Effects of HFRP Fibers Type. In Figures 9(a) and 9 (b), it can be seen that for an equal number of layers of HFRP, such as A2B2, C2B2, and C2A1G1, enhancement of strength and deformation ability of the confined specimens varies with type of HFRP. Among all the confined specimens, C/GFRP hybrid series display the greatest strength efficiency and show the highest ultimate compressive strength $f_{c c}^{\prime}$. There is not much difference in the strength confinement effectiveness of A/BFRP, C/BFRP, and B/GFRP series specimens. Among all the specimens, $\mathrm{C} / \mathrm{A} / \mathrm{GFRP}$ and $\mathrm{C} / \mathrm{B} / \mathrm{GFRP}$ series specimens show the lowest strength effectiveness and the lowest compressive strength $f_{c c}^{\prime}$ at failure.

Among all the hybrid specimens, the deformation capacity of A/BFRP series-confined specimens is the highest, followed by B/GFRP series, C/GFRP series, C/A/GFRP series, $\mathrm{C} / \mathrm{B} / \mathrm{GFRP}$ series, and C/BFRP series. The tensile test for HFRP plate shows that aramid fibers sheets have the best influence in enhancing toughness. On the other hand, for hybrids of three kinds of fiber sheets, that is, C/A/GFRP series and $\mathrm{C} / \mathrm{B} / \mathrm{GFRP}$ series, when loading is close to the ultimate bearing capacity, the $\sigma-\varepsilon$ curves begin to follow wavy pattern, whereby the outermost low ductility fibers fracture first, followed by those with higher ductility, and the confined specimen can reach a reasonable degree of ductility [34].

\section{Strength Model}

A comparison between measured compressive strength of confined specimens and calculated values using the four existing models, Samaan model [18], Toutanji model [12], Lam-Teng model [19], and Pham model [27], and the results are listed in Table 5.

From Table 5 we can see that the maximum strength ratio between test data and predicted values by Samaan model is 1.24 , the minimum value is 0.83 , and the average is 1.01 . Among the four models, Samaan model represented the best fit for the predicted strength. The strength maximum ratio between test data and calculated values by Toutanji model is 1.15 , the minimum value is 0.78 , and the average is 0.95 . The value by Toutanji model is relatively larger than the test results. The maximum ratio between test data and predicted values of Lam-Teng model is 1.67, the minimum is 1.08, and the average is 1.31 . The maximum strength ratio between strength test data and calculated values by Pham model is 1.90 , the minimum value is 1.22 , and the average is 1.50 . It 


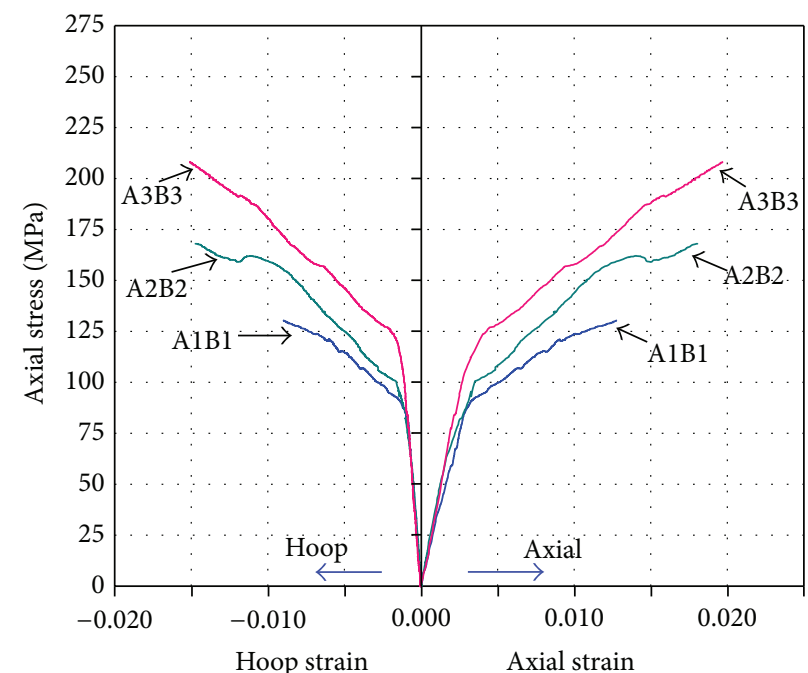

(a) UHPC-filled A/BFRP tubes

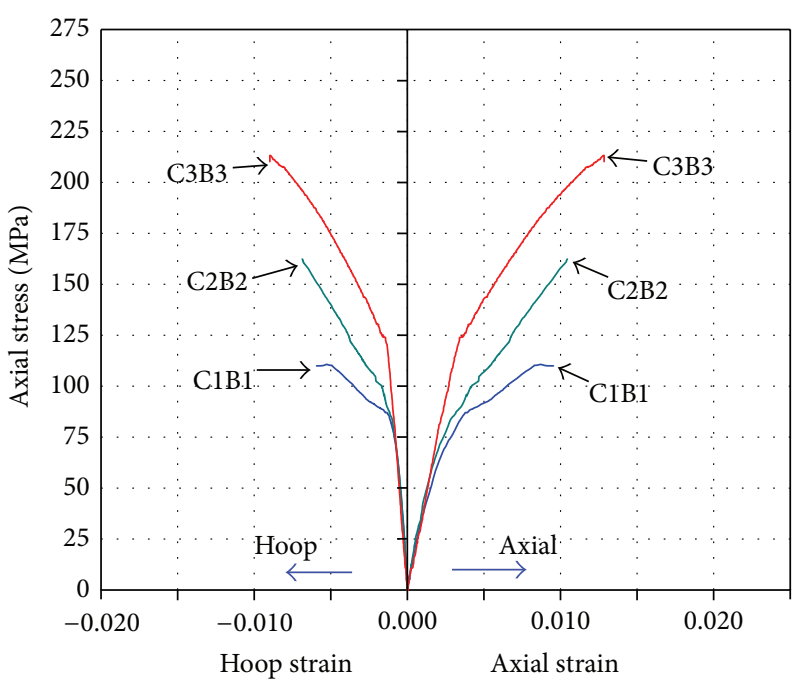

(c) UHPC-filled C/BFRP tubes

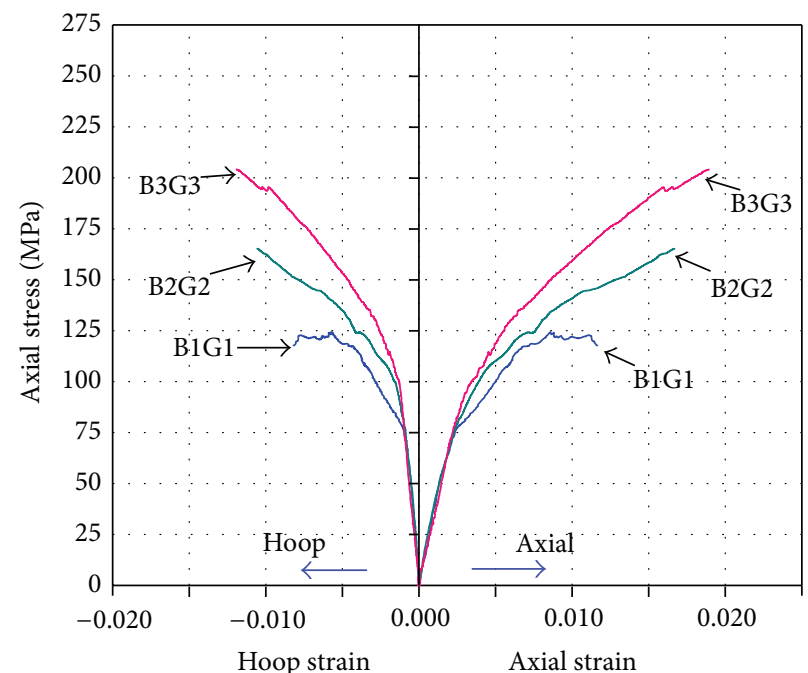

(b) UHPC-filled B/GFRP tubes

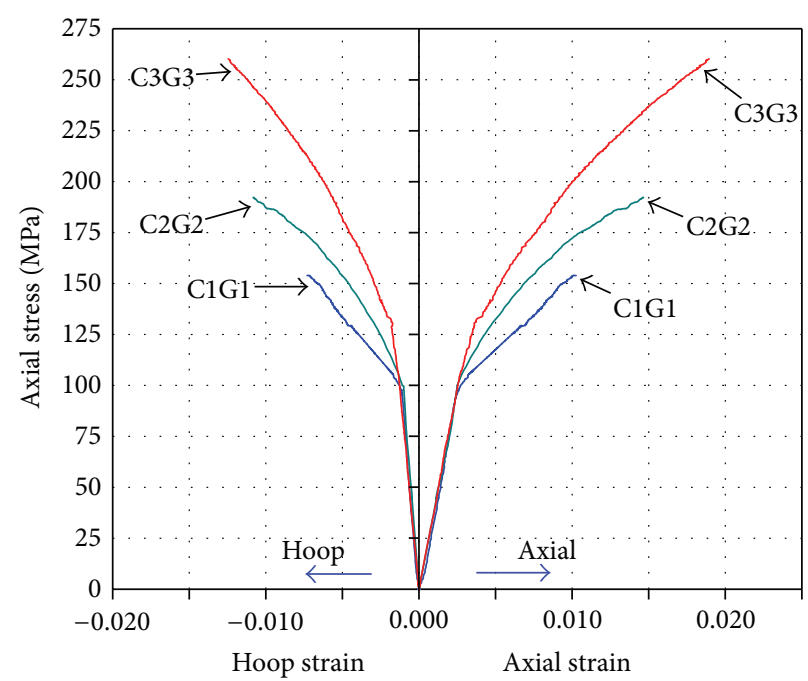

(d) UHPC-filled C/GFRP tubes

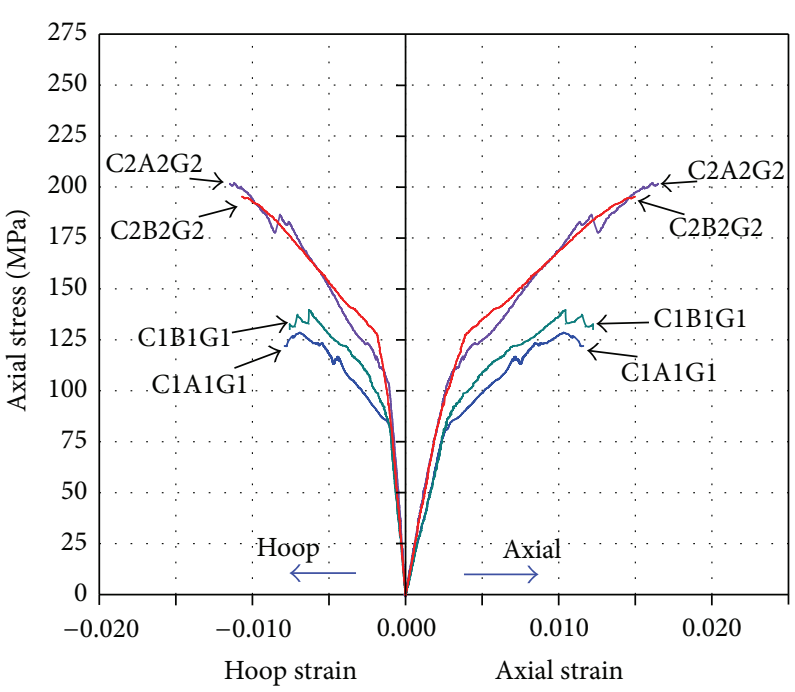

(e) UHPC-filled C/A/GFRP and C/B/GFRP tubes

FIGURE 8: Average stress-strain response curves for each group of confined UHPC specimens. 


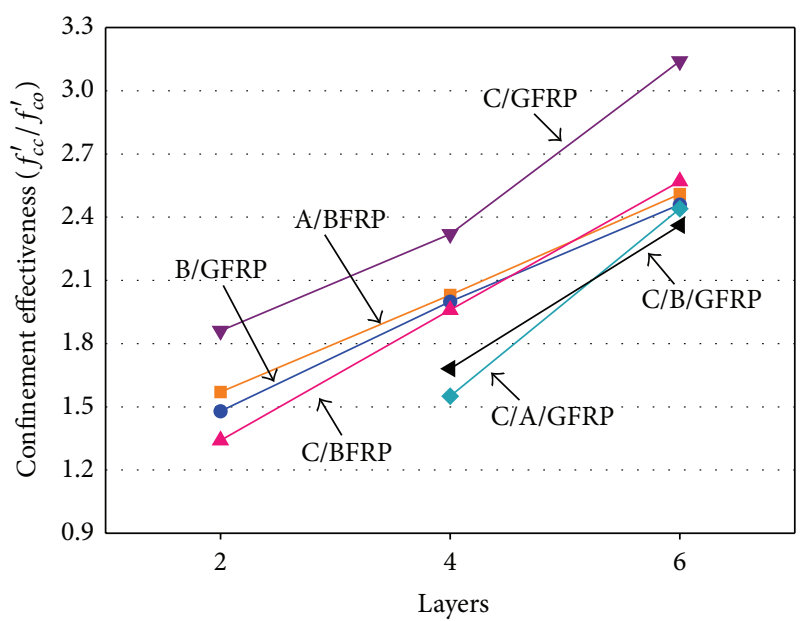

(a) Confinement effectiveness layers

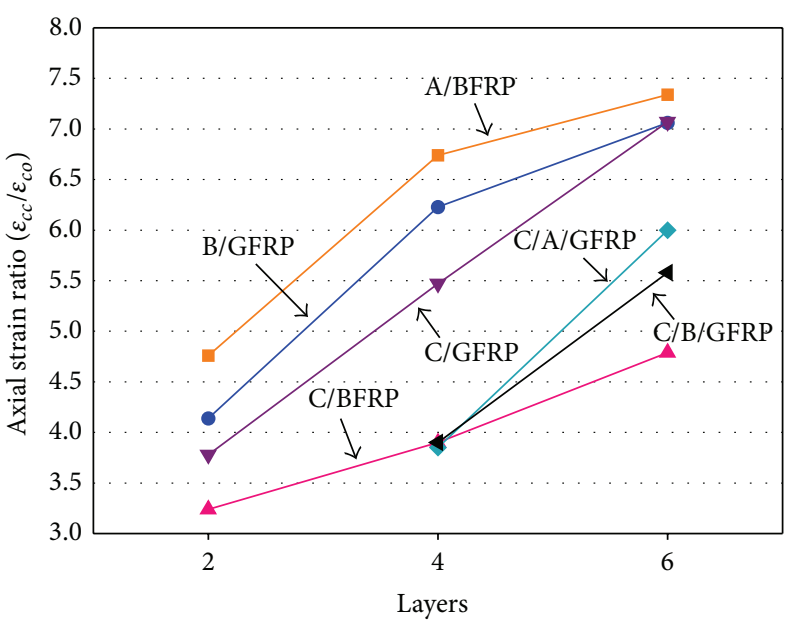

(b) Axial strain ratio layers

FIGURE 9: Average confinement effectiveness and axial strain ratio versus layers for each group of specimens.

TABLE 5: Comparison of confinement models for predicting compressive strength.

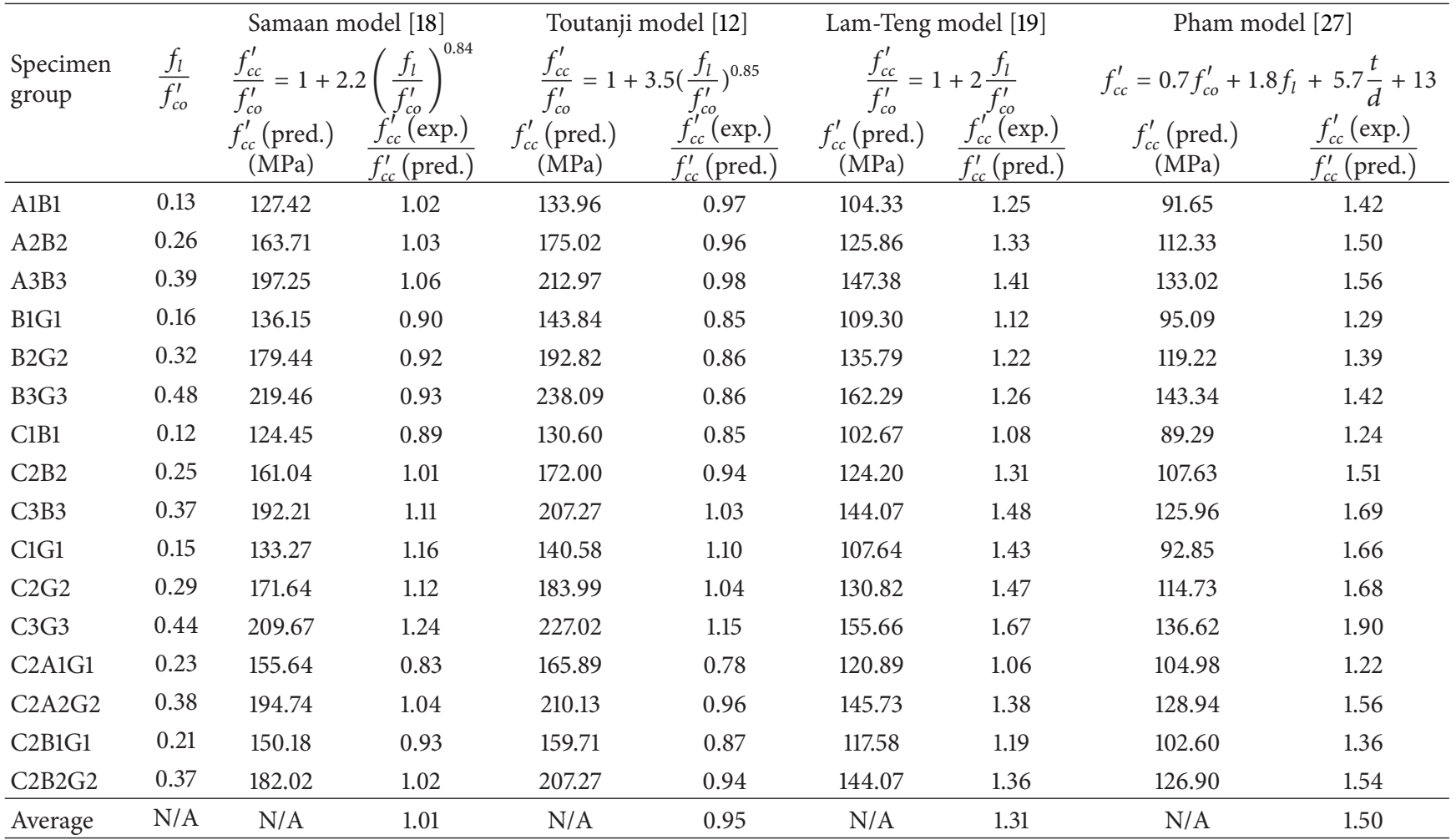

can be seen that the predicted value by Lam-Teng model and Pham model is relatively smaller than the test results.

Most of the above four models use the form $f_{c c}^{\prime} / f_{c o}^{\prime}=$ $1+\alpha\left(f_{l} / f_{c o}^{\prime}\right)^{\beta}$, which only takes into consideration the effect of confinement ratio $f_{l} / f_{c o}^{\prime}$ on strength, without considering the influence of HFRP types. It was found that, under the same confinement ratio, the type of hybrid FRP has a great influence on the compressive strength of specimen. In order to obtain a more accurate strength prediction model, the strength prediction model should consider the influence by each type of HFRP, in the fact that the $\alpha$ in model $f_{c c}^{\prime} / f_{c o}^{\prime}=$ $1+\alpha\left(f_{l} / f_{c o}^{\prime}\right)^{\beta}$ should be calculated separately. The different regression values $\alpha$ and $\beta$ for the respective types of hybrid fibers are shown in Table 6.

Figure 10 shows a comparison between the predictive values calculated by five strength models above and test measured values.

From Table 6, it can be seen that, for all the four series of UHPC-filled HFRP tubes, the fitting value of $\alpha$ is between 3.0 and 6.0, where the biggest value of $\alpha$ is obtained from C/BFRP 


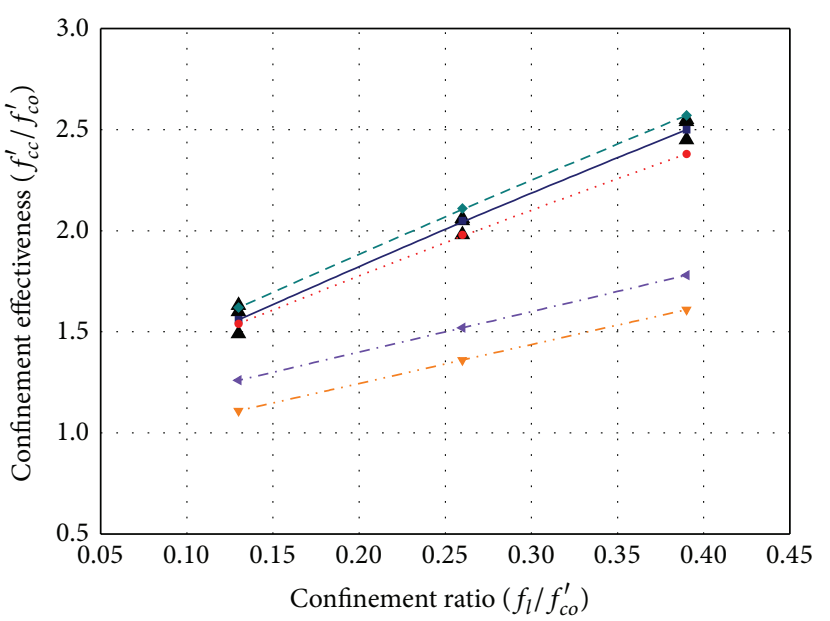

(a) UHPC-filled A/BFRP tubes

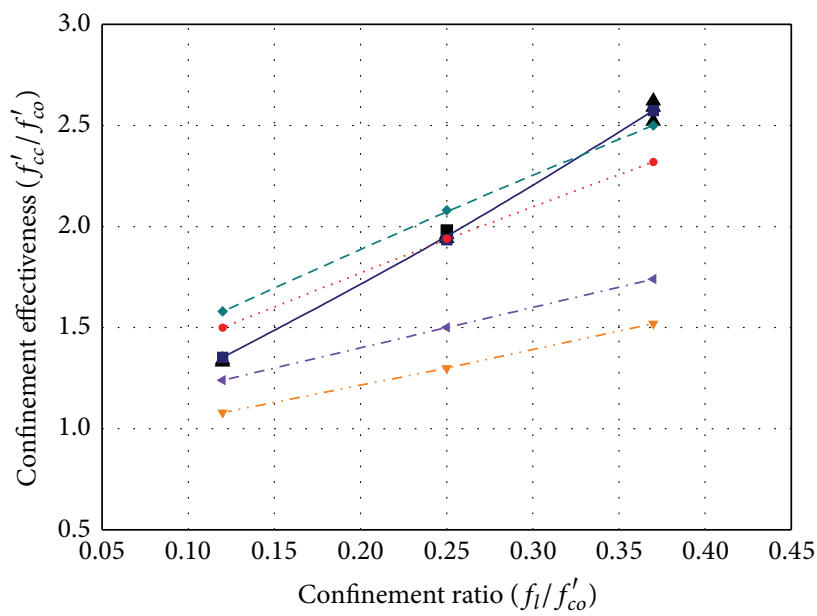

$\Delta$ Test data $\quad-\rightarrow$ Toutanji model [12]

$\rightarrow$ The proposed model $\quad$ - . Lam-Teng model [19]

-.. Samaan model [18] … Pham model [27]

(c) UHPC-filled C/BFRP tubes

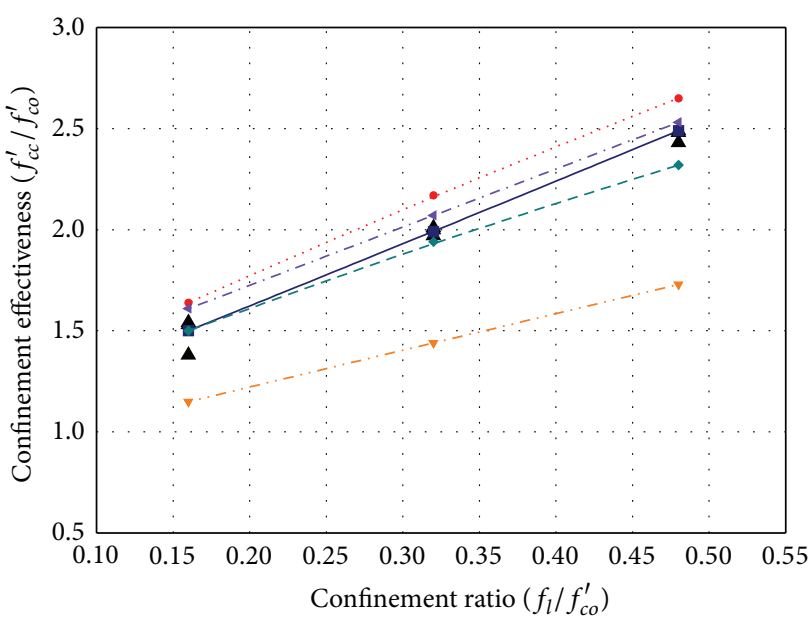

(b) UHPC-filled B/GFRP tubes

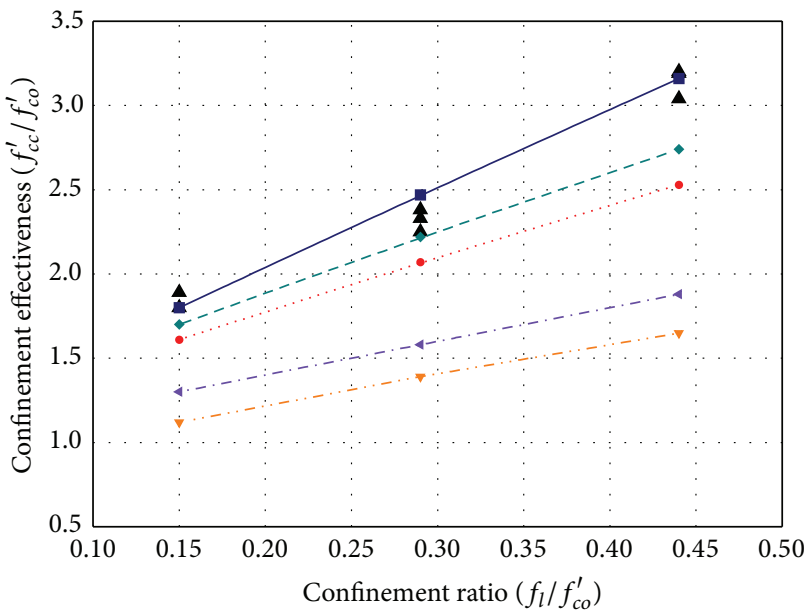

\ Test data $\quad-$ - Toutanji model [12]

$\rightarrow$ The proposed model $\quad$ - . Lam-Teng model [19]

-... Samaan model [18] … Pham model [27]

(d) UHPC-filled C/GFRP tubes

FIGURE 10: The fitting curves for strength of each group of specimens.

TABLE 6: The strength model parameters for each group of specimen.

\begin{tabular}{lccc}
\hline Specimen group & \multicolumn{2}{c}{ Model parameters } & The goodness of fit \\
& $\alpha$ & $\beta$ & $R^{2}$ \\
\hline A/BFRP series & 3.5 & 0.897 & 0.99 \\
B/GFRP series & 3.1 & 0.997 & 0.98 \\
C/BFRP series & 5.9 & 1.329 & 0.99 \\
C/GFRP series & 4.5 & 0.917 & 0.96 \\
\hline
\end{tabular}

series. This shows that the strength confinement efficiency increases with confinement ratio $f_{l} / f_{c o}^{\prime}$, and the enhancing degree of strength by C/BFRP hybrid series is the highest and then is followed by C/GFRP and then B/GFRP and A/BFRP hybrid series. The strength increasing rate of $\mathrm{B} / \mathrm{GFRP}$ and $\mathrm{A} / \mathrm{BFRP}$ is almost equal; increase in confinement ratio does not have significant effect on these two series. On the other hand, among the four different HFRP series-confined UHPC specimens, it is only C/BFRP series specimens where the value of $\beta$ is greater than 1 , while the rest of the hybrid FRP series' values of $\beta$ are less than 1 . This indicates that, within the confinement range studied here, the confinement effect $f_{c c}^{\prime} / f_{c o}^{\prime}$ of C/BFRP increases with the confinement ratio $f_{l} / f_{c o}^{\prime}$ by a gradually increasing gradient observed on the curve; however, the relationship between the confinement effect $f_{c c}^{\prime} / f_{c o}^{\prime}$ and confinement ratio $f_{l} / f_{c o}^{\prime}$ by the other HFRP series is almost linear.

From Table 6 and Figure 10, it can be observed that the proposed strength model shows a good fit for the test data; thus it can provide more accurate prediction of strength for the four different HFRP series specimens. In Figure 10, it also can be concluded that using Samaan model and Toutanji model to predict strength values for A/BFRP, B/GFRP, and 
$\mathrm{C} / \mathrm{BFRP}$ series specimen gives relatively accurate results, but for C/GFRP series specimens predicted values slightly lower than the test results. Using Lam-Teng model to predict strength values for A/BFRP, C/BFRP, and C/GFRP series specimens gives significantly lower values than the test results, while the predicted values for B/GFRP series specimens are slightly higher. And it also can be seen that the predicted values by Pham model are lower than the test results.

\section{Strain Model}

Four ultimate strain prediction models, Samaan model [18], Lam-Teng model [19], Toutanji model [12], and Pham model [27], are used to calculate the ultimate strain for UHPCfilled HFRP tube specimens. Table 7 shows the comparison between the calculated ultimate strainvalues and test data.

In Table 7, the maximum ratio between the measured axial ultimate strain and predicted values by Samaan model is 0.23 , the minimum ratio is 0.14 , and the average is 0.18 . That is, the model by Samaan consistently overestimated test results of ultimate strain with high errors. The maximum ratio between the measured ultimate strain and predicted values by Toutanji model is 0.52 , the minimum ratio is 0.22 , and the average is 0.35 , which shows that the predicted ultimate strain value using Toutanji model is also large and differs greatly with the measured value. The maximum ratio between the measured ultimate strain and predicted values by Lam-Teng model is 1.07 , the minimum ratio is 0.61 , and the average is 0.79 , which shows that predicted ultimate strain value using Lam-Teng model is relatively large, but among the three models it produces values closest to the measured values. And the average ratio between the measured ultimate strain and predicted values by Pham model is 2.25 , which shows that predicted ultimate strain value using Pham model is relatively small.

In order to more accurately predict the ultimate strain of UHPC-filled HFRP tube specimens, the confinement model should consider the effect of different types of hybrid FRP series. The formula for calculating ultimate strain is given in the form $\varepsilon_{c c} / \varepsilon_{c o}=\alpha+\beta\left(E_{f} t / E_{\text {seco } o} R\right)\left(\varepsilon_{f} / \varepsilon_{c o}\right)^{\gamma}$. The fitting values for corresponding types of hybrid FRP series are listed in Table 8.

From Table 8 it can be seen that the value of $\alpha$ for different types of hybrid FRP series is between 1.9 and 3.7, $\beta$ is between 2.2 and 2.8, while $\gamma$ is between 1.4 and 1.7. The maximum ratio between measured ultimate strain and calculated results is 1.07 , the minimum is 0.95 , and the average is 1.00 , which shows great accuracy in the predicted values.

\section{Constitutive Model}

By taking into account the deformation characteristics of UHPC-filled HFRP tubes under axial compression, this paper assumes the following. (1) The $\sigma-\varepsilon$ curve is divided into three stages: stage I is the linear stage, where the gradient is equal to the elastic modulus of unconfined UHPC; stage II is the transition segments, where the $\sigma-\varepsilon$ curve begins to bend; stage III is linear hardening segment. (2) The first and the second and the second and the third segments are all smoothly connected. The close-form constitutive model for the three-stage curves is as follows:

$$
\begin{gathered}
\sigma_{c}=E_{c} \cdot \varepsilon_{c}, \quad \text { for } 0 \leq \varepsilon_{c}<\varepsilon_{p}, \\
\sigma_{c}=\frac{E_{c}^{2}+E_{2}^{2}}{2 E_{2}} \cdot \varepsilon_{c}-\frac{\left(E_{c}-E_{2}\right)^{2} \cdot E_{c}}{4 f_{o} E_{2}} \cdot \varepsilon_{c}^{2}-\frac{\left(E_{c}-E_{2}\right)^{2} \cdot f_{o}}{4 E_{c} E_{2}}, \\
\quad \text { for } \varepsilon_{p} \leq \varepsilon_{c}<\varepsilon_{t}, \\
\sigma_{c}=f_{o}+\varepsilon_{c} \cdot E_{2}, \quad \text { for } \varepsilon_{t} \leq \varepsilon_{c} \leq \varepsilon_{c c},
\end{gathered}
$$

where $\sigma_{c}$ is the axial stress and $\varepsilon_{c}$ is the axial strain; $E_{c}$ is the elastic modulus of unconfined UHPC; $f_{o}$ is the point at which the third section of the curve intersects with the $\sigma_{c}$ axis when extended, given by $f_{o}=f_{c o}^{\prime}[35]$ and $E_{2}$ is the gradient of the third linear segment, which is given by

$$
E_{2}=\frac{f_{c c}^{\prime}-f_{c o}^{\prime}}{\varepsilon_{c c}} .
$$

The first linear segment meets the second transition segment at $\varepsilon_{p}$, and the second segment meets the third linear segment $\varepsilon_{t}$, which is given by

$$
\begin{gathered}
\varepsilon_{p}=\frac{f_{o}}{E_{c}} \\
\varepsilon_{t}=\frac{f_{o} \cdot\left(E_{c}+E_{2}\right)}{E_{c} \cdot\left(E_{c}-E_{2}\right)} .
\end{gathered}
$$

In this new proposed constitutive model, the values for $f_{c c}^{\prime}$ and $\varepsilon_{c c}$ are calculated using the formulas in Tables 6 and 8 . Figure 11 compares the stress-strain response of HFRP specimen groups with the proposed stress-strain model and the two existing constitutive models by Samaan et al. [18] and Lam and Teng [19].

It can be seen from Figure 11 that the $\sigma-\varepsilon$ curves of Samaan model and Lam-Teng model are significantly below the test curves, where curve of Samaan model is the lowest. The gradient of the two models at the third segment is smaller than the test results; that is, the existing models do not accurately predict the stress-strain response of HFRPconfined UHPC. These existing models were generally developed for FRP-confined normal concrete. There are differences in the stress-strain response between UHPC and normal concrete. The initial ascending portion is linear for HFRPconfined UHPC but parabolic for normal concrete. The existing confinement models are based on normal concrete confined with FRP, while the gradient of UHPC-filled HFRP is higher than confined normal concrete at the last stage. The curves obtained using the proposed constitutive models are quite close to the experimental results. The curves for some of the specimens deviate from the test curves after passing the transition stage, which is because in the proposed model of this paper $f_{o}=f_{c o}^{\prime}$, but actually $f_{o}$ is not exactly equal to $f_{c o}^{\prime}$. In the test data, some of the actual values of $f_{o} / f_{c o}^{\prime}$ are 


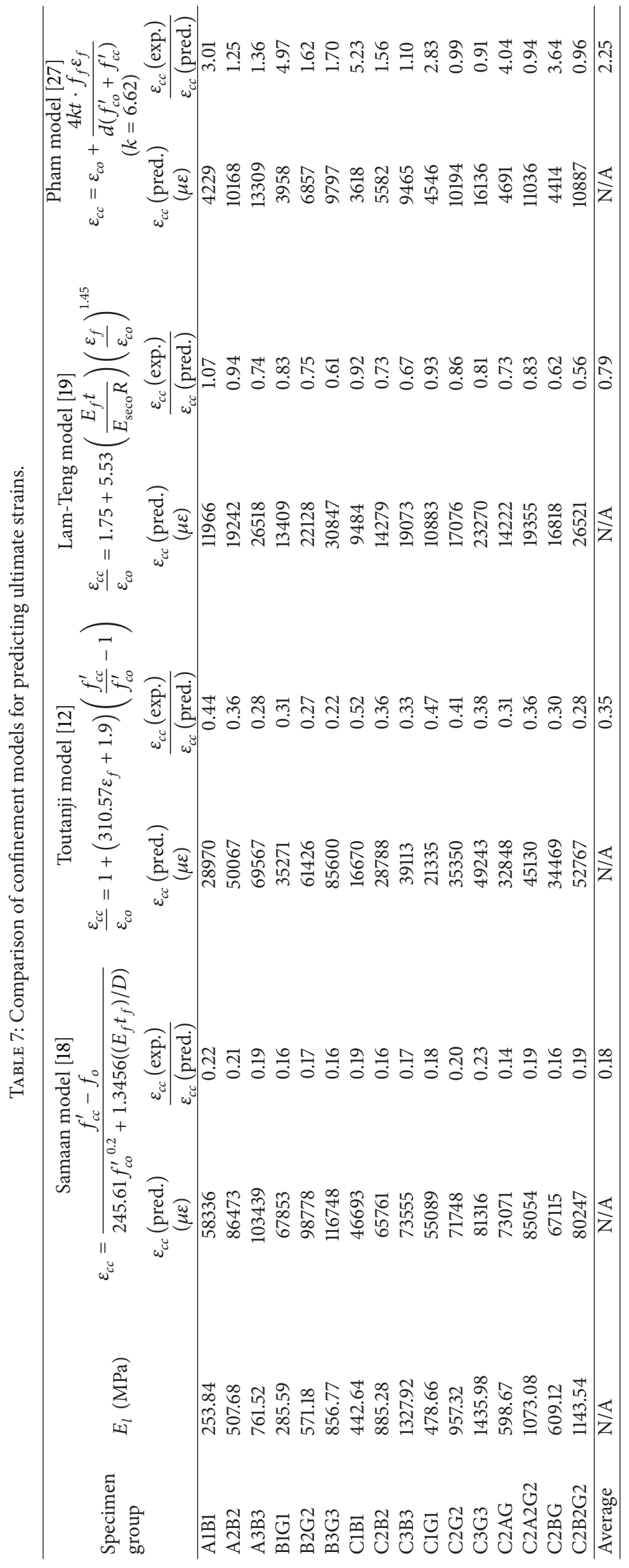


TABLE 8: The strain fitting model for each group of specimens.

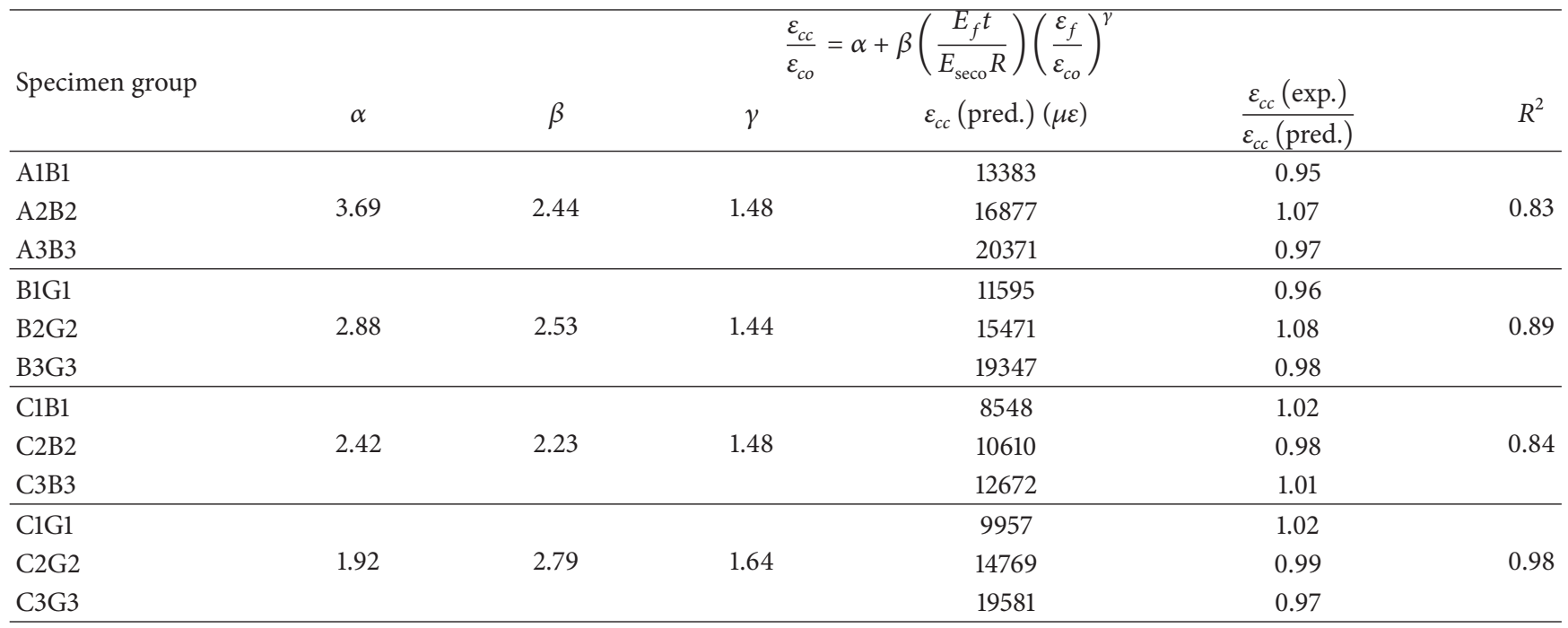

less than 1.0, which will cause the gradient of the proposed model curves at the third segment to be smaller, such that after the transition phase of the proposed model the curve becomes slightly above the test curves, as seen for B1G1 and C1B1. On the other hand, the actual values of $f_{o} / f_{c o}^{\prime}$ for some of the specimens are greater than 1.0, which makes the gradient of the proposed model curve at the third phase of the curves larger. This makes the curves become below the test curves after passing the transition segment, as shown by A3B3, C3G3.

\section{Conclusion}

Most of UHPC-filled HFRP tube specimens failed with rupture of HFRP tube at or near the midheight. The local rupture of HFRP tubes did not lead to explosive failure of UHPC cylinder, and its ductility is better than that of UHPC confined by only one type of FRP. HFRP tube can effectively improve the compressive strength and ultimate strain of UHPC specimens. The main factors affecting the axial compression performance of HFRP-confined UHPC specimen are the number of fiber sheet layers and type of hybrid fiber. The confinement effectiveness of strength and deformation capacity increases with the fiber sheet layers. In all kinds of hybrid FRP, the highest strength confinement effectiveness is produced by C/GFRP series, while the maximum deformation capacity is from A/BFRP series.

For HFRP-confined UHPC specimen, the strength prediction value by Samaan model is close to experimental data, whereas strength prediction value by Toutanji model is lower but by Lam-Teng model is higher than the test results. The strength of HFRP-confined specimen is influenced by not only the confined stress but also the type of hybrid FRP series. The proposed strength model, considering type of hybrid fiber series, is presented to provide more accurate prediction of the test results.

The values of the three existing ultimate strain prediction models are larger than the experimental values, whereby
Lam-Teng model values are closer to experimental values. The proposed ultimate strain model based on the different types of hybrid fiber sheets has high prediction accuracy.

The stress-strain curves obtained by Samaan and LamTeng model are lower than that of test curves, while the new proposed close-form model of three phases produces relatively accurate values.

\section{Notations}

$f_{l}: \quad$ Lateral confinement strength of HFRP tube

$E_{l}: \quad$ Lateral confinement stiffness of HFRP tube

$f_{f}$ : Actual hoop tensile strength of HFRP

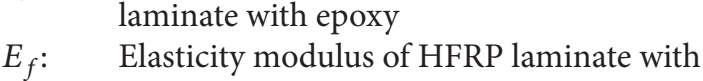
epoxy

$\varepsilon_{f}$ : Actual hoop ultimate tensile strain of

HFRP laminate with epoxy

$t$ : Thickness of HFRP laminate with epoxy

$D: \quad$ Internal diameter of HFRP tube

$f_{c o}$ : Compressive strength of unconfined UHPC

$f_{l} / f_{c o}^{\prime}:$ Confinement ratio

$f_{c c}^{\prime} / f_{c o}^{\prime}$ : Confinement effectiveness

$\varepsilon_{c c} / \varepsilon_{c o}:$ Axial strain ratio

$\varepsilon_{c o}$ : Axial strain of unconfined UHPC specimens corresponding to $f_{c o}^{\prime}$

$\varepsilon_{c c}: \quad$ Ultimate strain of UHPC-filled HFRP tube specimens

$f_{c c}^{\prime}$ : Ultimate compressive strength of

UHPC-filled HFRP tube specimens

$E_{c}: \quad$ Elastic modulus of unconfined UHPC

$f_{o}: \quad \sigma$ point at which the curve at the third phase, when extended, intersects with the $\sigma$ axis 


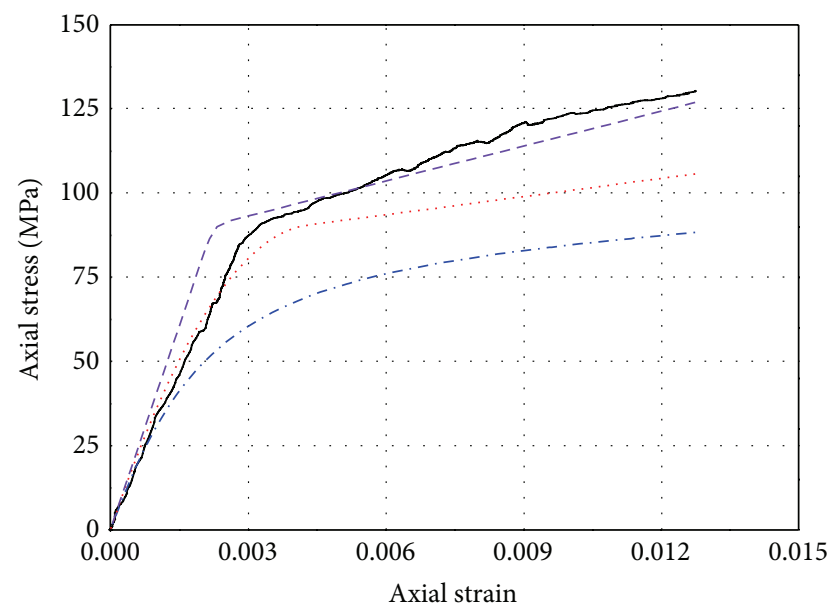

$\begin{array}{llll} & \text { Test data } & \ldots . . & \text { Lam-Teng model [19] } \\ \text { _._. } & \text { Samaan model [18] } & \ldots-- & \text { The proposed model }\end{array}$

(a) A1B1

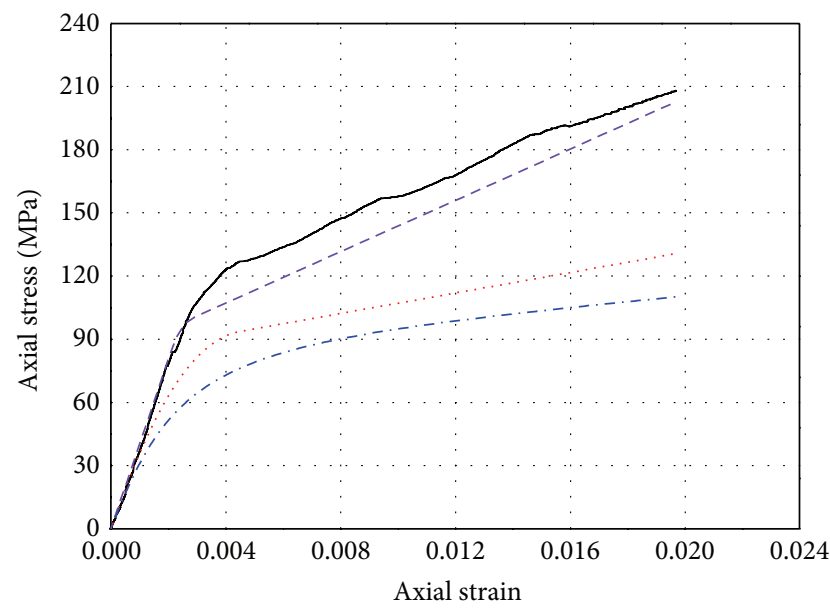

— Test data

Samaan model [18]

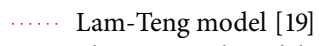

- - The proposed model

(c) $\mathrm{A} 3 \mathrm{~B} 3$

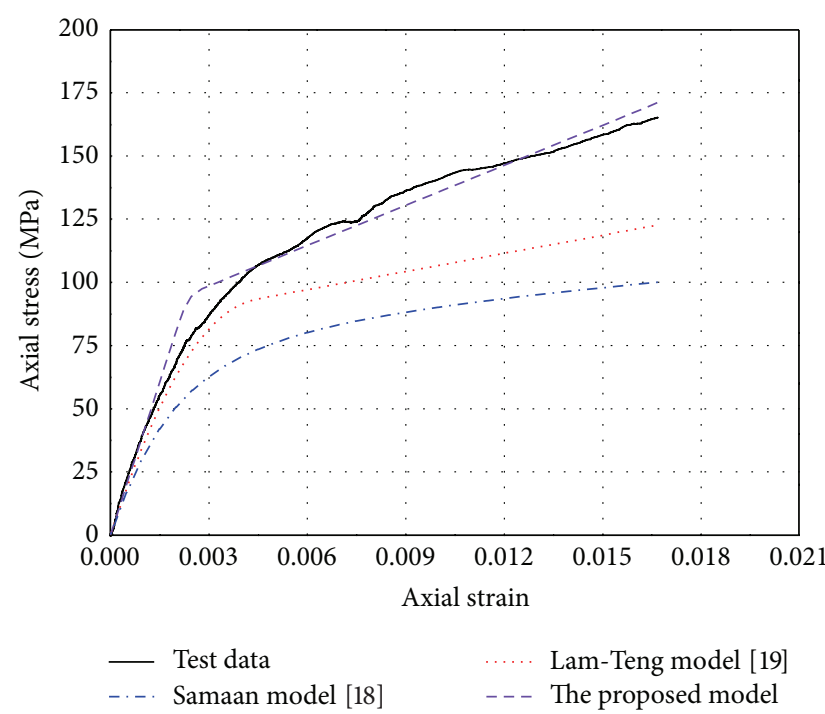

(e) B2G2

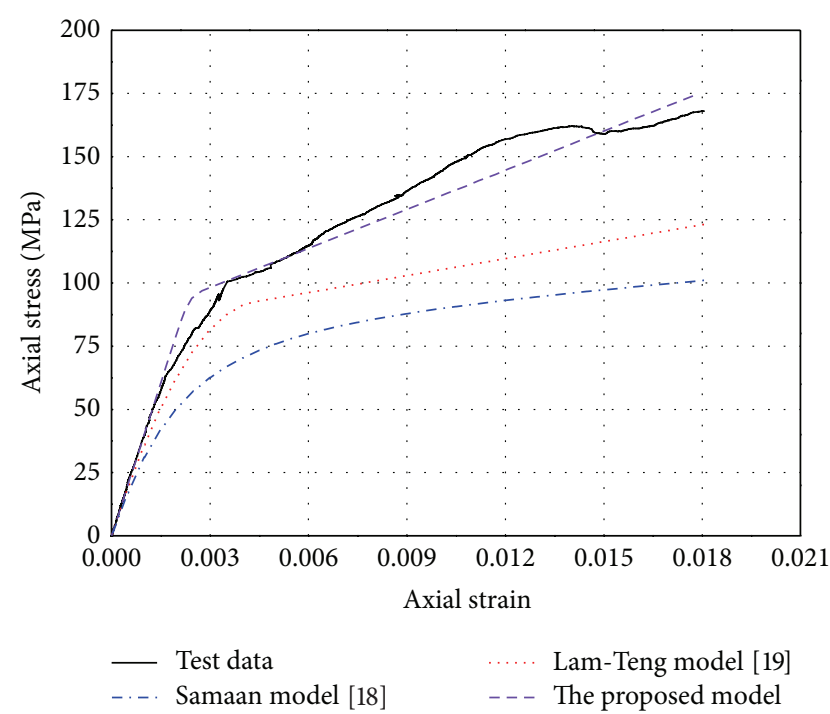

(b) A2B2

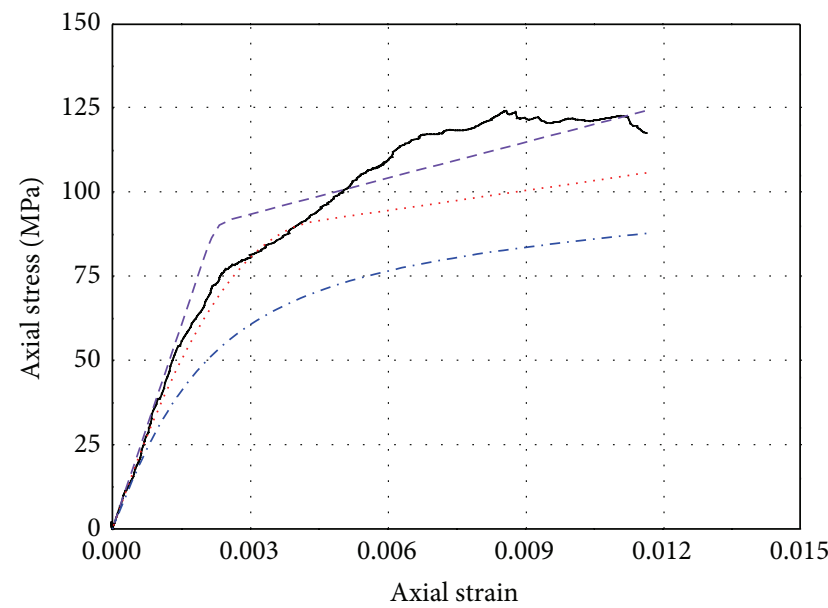

$\begin{array}{llll} & \text { Test data } & \ldots . . & \text { Lam-Teng model [19] } \\ \ldots & \text { Samaan model }[18] & \ldots & \text { The proposed model }\end{array}$

(d) B1G1

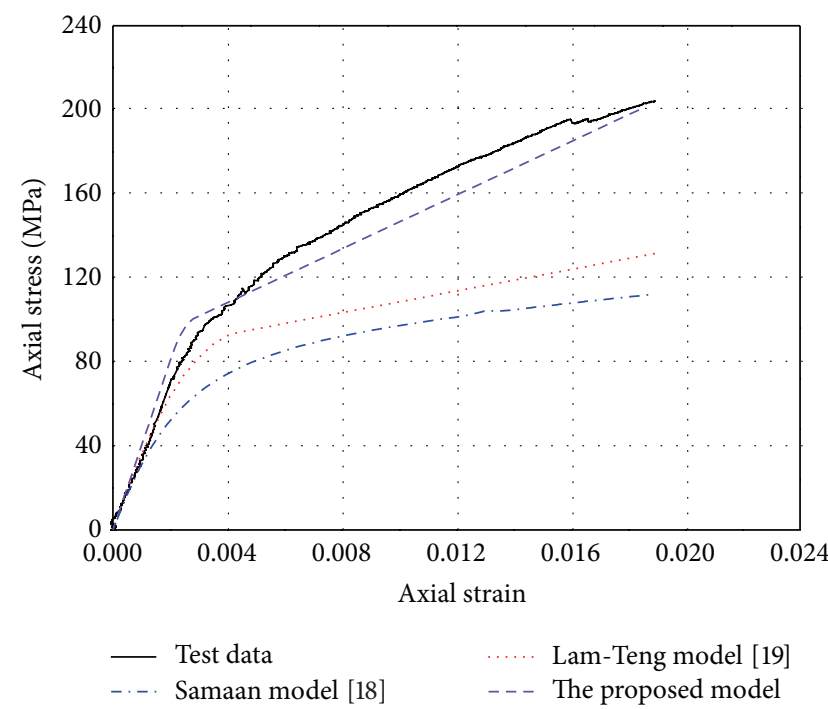

(f) B3G3

FIGURE 11: Continued. 


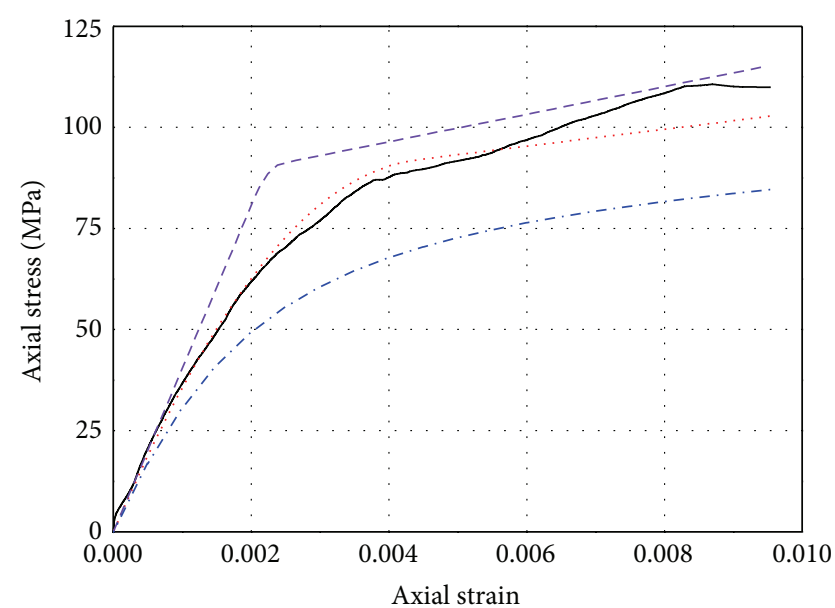

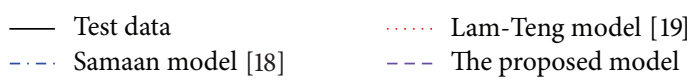

(g) $\mathrm{C} 1 \mathrm{~B} 1$

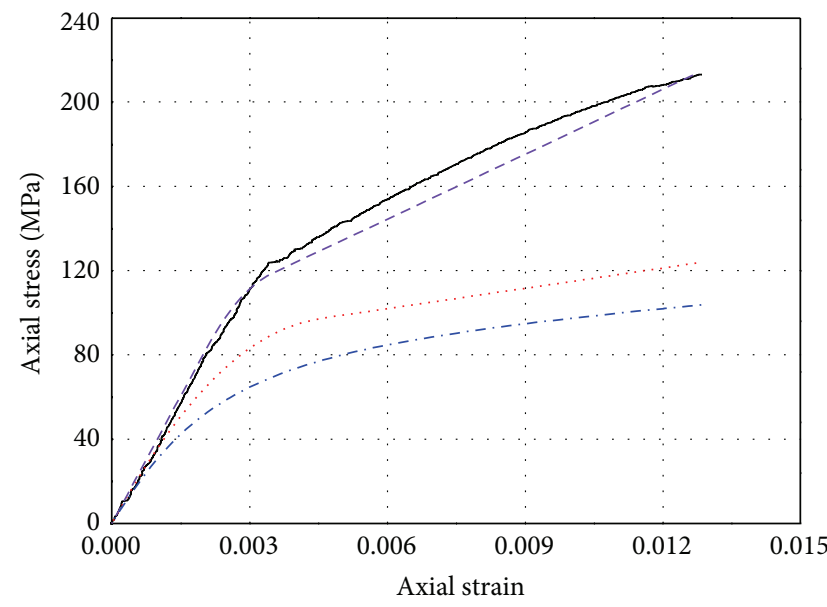

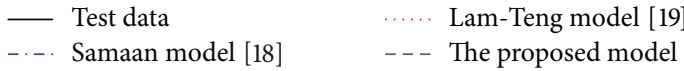

(i) $\mathrm{C} 3 \mathrm{~B} 3$

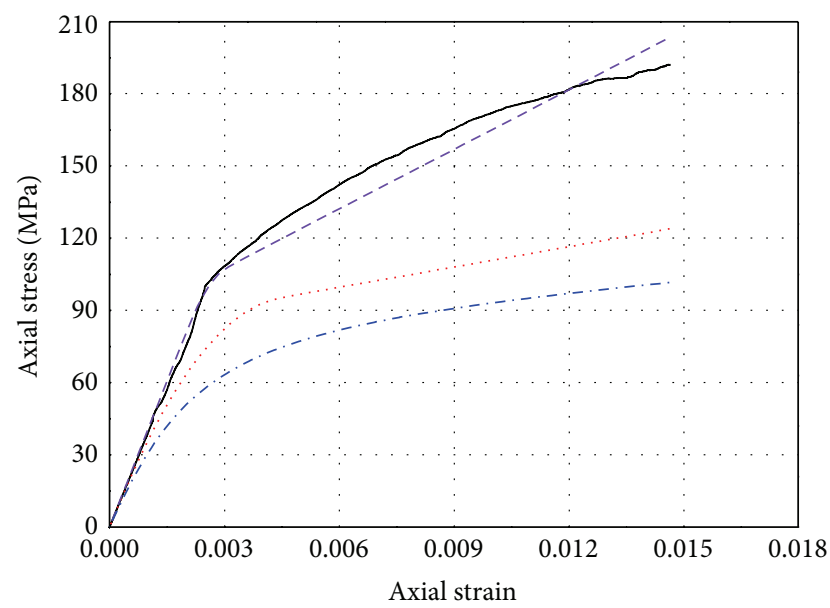

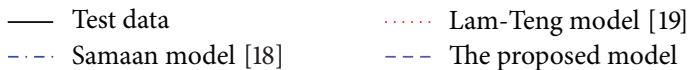

(k) $\mathrm{C} 2 \mathrm{G} 2$

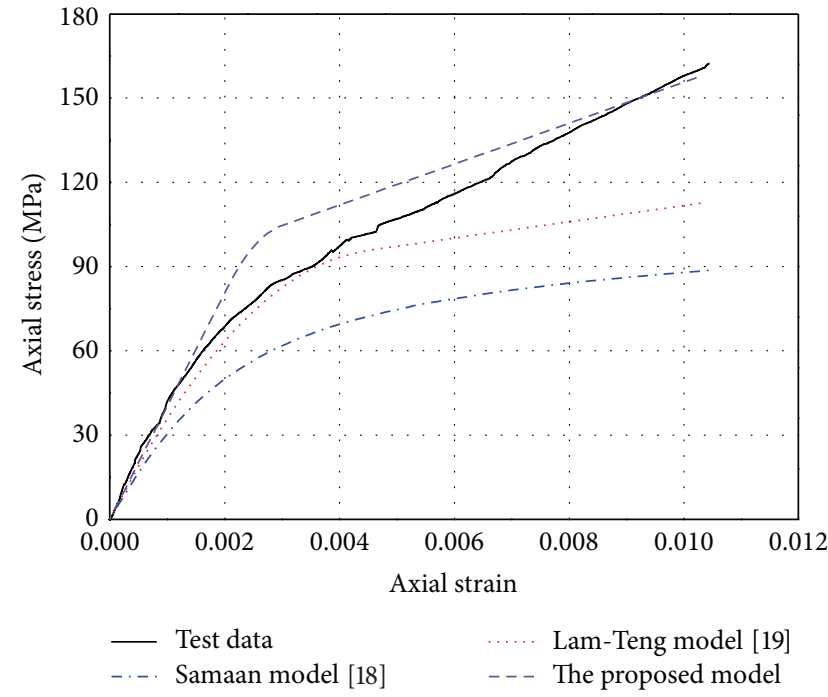

(h) $\mathrm{C} 2 \mathrm{~B} 2$

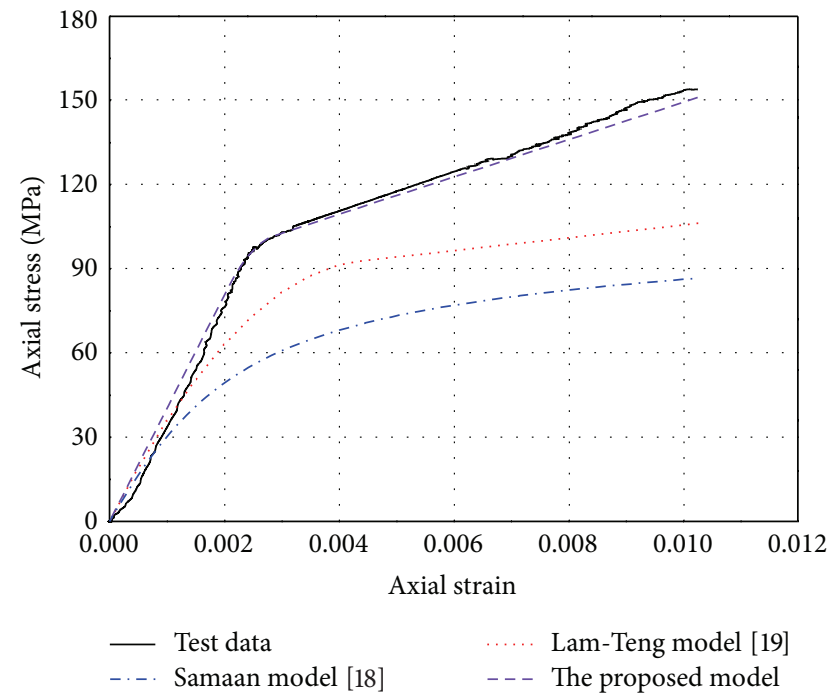

(j) $\mathrm{ClG1}$

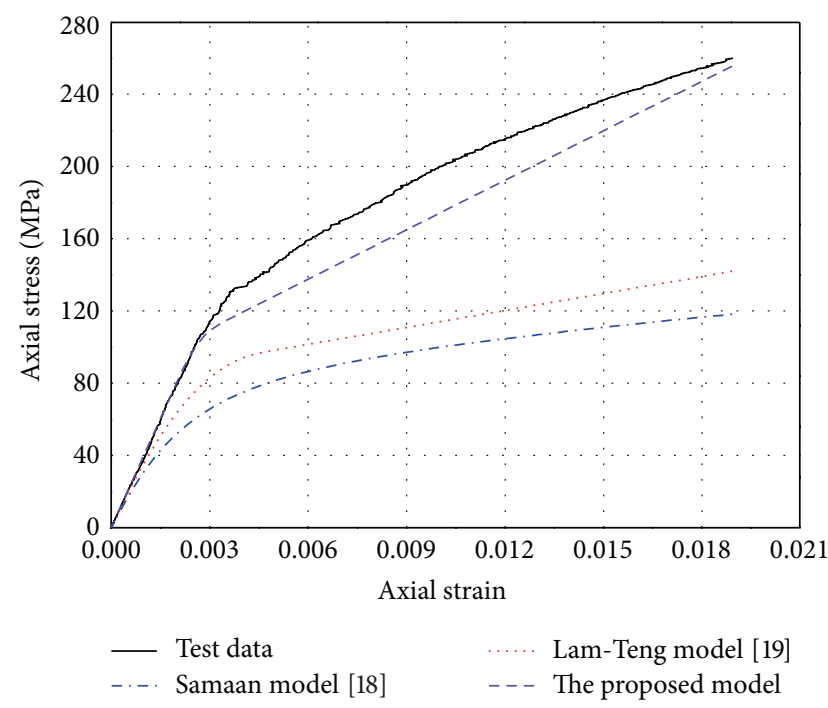

(l) $\mathrm{C} 3 \mathrm{G} 3$

FIGURE 11: Comparison of stress-strain predictions for specimens. 


\author{
$E_{2}:$ Gradient of the third linear segment of $\sigma-\varepsilon$ \\ curve \\ $\varepsilon_{p}: \varepsilon$ point at which the first linear segment \\ meets the second transition segment of \\ $\sigma-\varepsilon$ curve \\ $\varepsilon_{t}: \varepsilon$ point at which the second segment meets \\ the third linear segment of $\sigma-\varepsilon$ curve.
}

\section{Conflict of Interests}

The authors declare that there is no conflict of interests regarding the publication of this paper.

\section{Acknowledgments}

This work was performed under a grant from the Natural Science Foundation of Beijing (Grant no. 8142005) and a grant from the Nation Natural Science Foundation of China (Grant no. 51378032).

\section{References}

[1] Y. L. Voo, S. J. Foster, and R. I. Gilbert, "Shear strength of fiber reinforced reactive powder concrete prestressed girders without stirrups," Journal of Advanced Concrete Technology, vol. 4, no. 1, pp. 123-132, 2006.

[2] T. Ozbakkaloglu, "Axial compressive behavior of square and rectangular high-strength concrete-filled FRP tubes," Journal of Composites for Construction, vol. 17, no. 1, pp. 151-161, 2013.

[3] T. Ozbakkaloglu, "Compressive behavior of concrete-filled FRP tube columns: assessment of critical column parameters," Engineering Structures, vol. 51, pp. 188-199, 2013.

[4] L. de Lorenzis and R. Tepfers, "Comparative study of models on confinement of concrete cylinders with fiber-reinforced polymer composites," Journal of Composites for Construction, vol. 7, no. 3, pp. 219-237, 2003.

[5] B. Binici, "An analytical model for stress-strain behavior of confined concrete," Engineering Structures, vol. 27, no. 7, pp. 1040-1051, 2005.

[6] L. A. Bisby, A. J. S. Dent, and M. F. Green, "Comparison of confinement models for fiber-reinforced polymer-wrapped concrete," ACI Structural Journal, vol. 102, no. 1, pp. 62-72, 2005.

[7] M. N. Youssef, M. Q. Feng, and A. S. Mosallam, "Stress-strain model for concrete confined by FRP composites," Composites Part B: Engineering, vol. 38, no. 5-6, pp. 614-628, 2007.

[8] A. Mirmiran, M. Shahawy, M. Samaan, H. El Echary, J. C. Mastrapa, and O. Pico, "Effect of column parameters on FRPconfined concrete," Journal of Composites for Construction, vol. 2, no. 4, pp. 175-185, 1998.

[9] M. Saafi, H. A. Toutanji, and Z. Li, "Behavior of concrete columns confined with fiber reinforced polymer tubes," ACI Materials Journal, vol. 96, no. 4, pp. 500-509, 1999.

[10] A. Z. Fam and S. H. Rizkalla, "Behavior of axially loaded concrete-filled circular fiber-reinforced polymer tubes," ACI Structural Journal, vol. 98, no. 3, pp. 280-289, 2001.

[11] W.-K. Kong and H.-C. Kim, "Behavior of concrete columns confined by carbon composite tubes," Canadian Journal of Civil Engineering, vol. 31, no. 2, pp. 178-188, 2004.
[12] H. A. Toutanji, "Stress-strain characteristics of concrete columns externally confined with advanced fiber composite sheets," ACI Materials Journal, vol. 96, no. 3, pp. 397-404, 1999.

[13] S. H. Ahmad and S. P. Khaloo, "Stress-strain curves of concrete confined by spiral reinforcement," ACI Materials Journal, vol. 79, no. 6, pp. 484-490, 1982.

[14] E. Hognestad, A Study of Combined Bending and Axial Load in Reinforced Concrete Members, University of Illinois Engineering Experiment Station, Bulletin Series no. 399, University of Illinois, Urbana, Ill, USA, 1951.

[15] R. M. Richard and B. J. Abbottt, "Versatile elastic-plastic stressstrain formula," ASCE Journal of the Engineering Mechanics Division, vol. 101, no. 4, pp. 511-515, 1975.

[16] D. A. Moran and C. P. Pantelides, "Stress-strain model for fiberreinforced polymer-confined concrete," Journal of Composites for Construction, vol. 6, no. 4, pp. 233-240, 2002.

[17] Z. Yan and C. P. Pantelides, "Design-oriented model for concrete columns confined with bonded FRP jackets or posttensioned FRP shells," in Proceedings of the 8th International Symposium on Fiber Reinforced Polymer Reinforcement for Concrete Structures, University of Patras, Patras, Greece, 2007.

[18] M. Samaan, A. Mirmiran, and M. Shahawy, "Model of concrete confined by fiber composites," Journal of Structural Engineering, vol. 124, no. 9, pp. 1025-1031, 1998.

[19] L. Lam and J. G. Teng, "Design-oriented stress-strain model for FRP-confined concrete," Construction and Building Materials, vol. 17, no. 6-7, pp. 471-489, 2003.

[20] H. Saadatmanesh, M. R. Ehsani, and M. W. Li, "Strength and ductility of concrete columns externally reinforced with fiber composite straps," ACI Structural Journal, vol. 91, no. 4, pp. 434447, 1994.

[21] J. C. Lim and T. Ozbakkaloglu, "Confinement model for FRPconfined high-strength concrete," Journal of Composites for Construction, vol. 18, no. 4, pp. 2-19, 2014.

[22] K. Miyauchi, S. Inoue, T. Kuroda, and A. Kobayashi, "Strengthening effects with carbon fiber sheet for concrete column," Proceedings of the Japan Concrete Institute, vol. 21, no. 3, pp. 1453-1458, 1999.

[23] S. Mandal, A. Hoskin, and A. Fam, "Influence of concrete strength on confinement effectiveness of fiber-reinforced polymer circular jackets," ACI Structural Journal, vol. 102, no. 3, pp. 383-392, 2005

[24] J. F. Berthet, E. Ferrier, and P. Hamelin, "Compressive behavior of concrete externally confined by composite jackets. Part B: modeling," Construction and Building Materials, vol. 20, no. 5, pp. 338-347, 2006.

[25] C. Cui and S. A. Sheikh, "Analytical model for circular normaland high-strength concrete columns confined with FRP," Journal of Composites for Construction, vol. 14, no. 5, pp. 562-572, 2010.

[26] Q. G. Xiao, J. G. Teng, and T. Yu, "Behavior and modeling of confined high-strength concrete," Journal of Composites for Construction, vol. 14, no. 3, pp. 249-259, 2010.

[27] T. M. Pham and M. N. S. Hadi, "Confinement model for FRP confined normal- and high-strength concrete circular columns," Construction and Building Materials, vol. 69, pp. 8390, 2014.

[28] R. Xiao, Z.-C. Deng, and C. L. Shen, "Properties of ultra high performance concrete containing superfine cement and without silica fume," Journal of Advanced Concrete Technology, vol. 12, no. 2, pp. 73-81, 2014. 
[29] G. Fischer, H. Fukuyama, and V. C. Li, "Effect of matrix ductility on the performance of reinforced ECC column members under reversed cyclic loading conditions," in Proceedings of the JCI International Workshop on Ductile Fiber Reinforced Cementitious Composites: Application and Evaluation (DRFCC '02), pp. 269-278, Advanced Civil Engineering-Materials Research Laboratory, University of Michigan, Ann Arbor, Mich, USA, 2002.

[30] S. L. Billington and J. Yoon, "Cyclic behavior of precast posttensioned segmental concrete columns with ECC," in Proceedings of the JCI International Workshop on Ductile Fiber Reinforced Cementitious Composites (DFRCC): Application and Evaluation (DFRCC-2002), Takayama, Japan, October 2002, pp. 279-288, Japan Concrete Institute, 2002.

[31] P. Zohrevand and A. Mirmiran, "Behavior of ultra-high performance concrete confined by fiber-reinforced polymers," Journal of Materials in Civil Engineering, vol. 23, no. 12, pp. 1727-1734, 2011.

[32] P. Zohrevand and A. Mirmiran, "Cyclic behavior of hybrid columns made of ultra-high performance concrete and fiber reinforced polymers," Journal of Composites for Construction, vol. 16, no. 1, pp. 91-99, 2012.

[33] J.-G. Dai, Y.-L. Bai, and J. G. Teng, "Behavior and modeling of concrete confined with FRP composites of large deformability," Journal of Composites for Construction, vol. 15, no. 6, pp. 963973, 2011.

[34] Z. C. Deng and J. H. Li, "Hybrid fiber reinforced plastics and properties for strengthening concrete structures," Fiber Reinforced Plastics/Composites, vol. 4, no. 1, pp. 50-54, 2006 (Chinese).

[35] J. G. Teng, T. Jiang, L. Lam, and Y. Z. Luo, "Refinement of a design-oriented stress-strain model for FRP-confined concrete," Journal of Composites for Construction, vol. 13, no. 4, pp. 269278, 2009. 

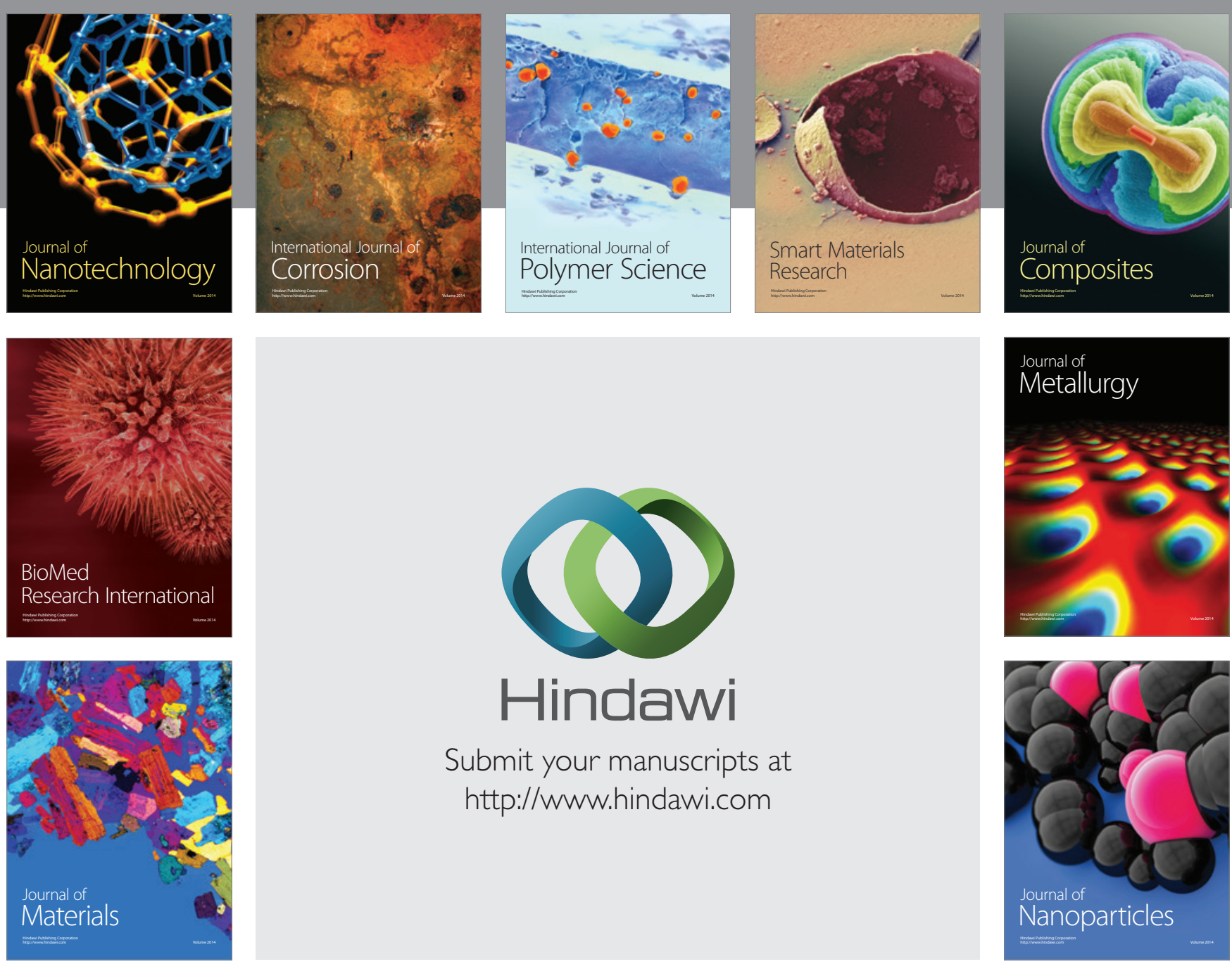

Submit your manuscripts at http://www.hindawi.com
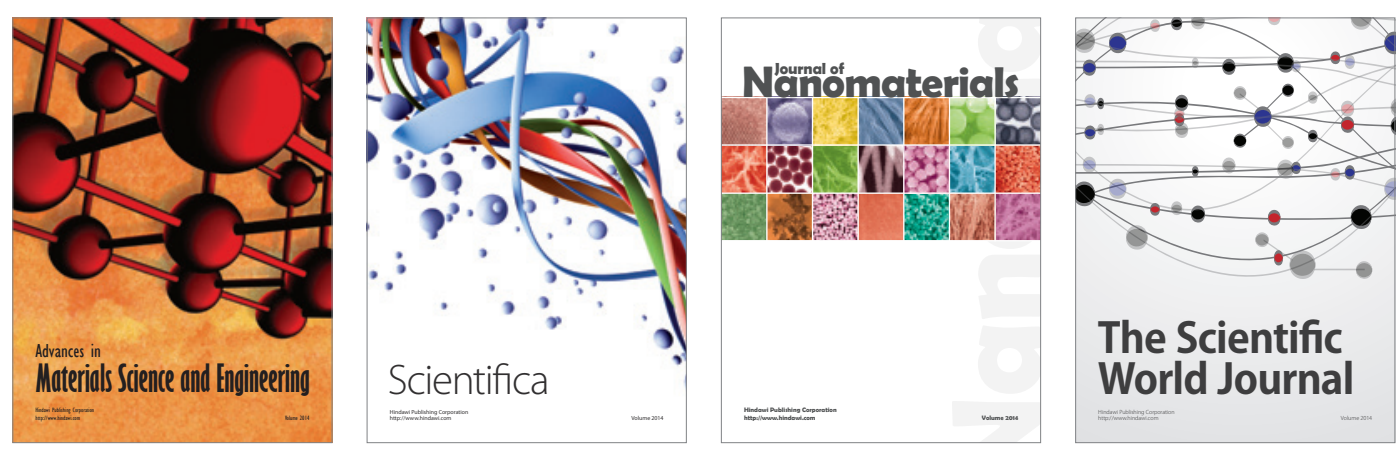

\section{The Scientific World Journal}
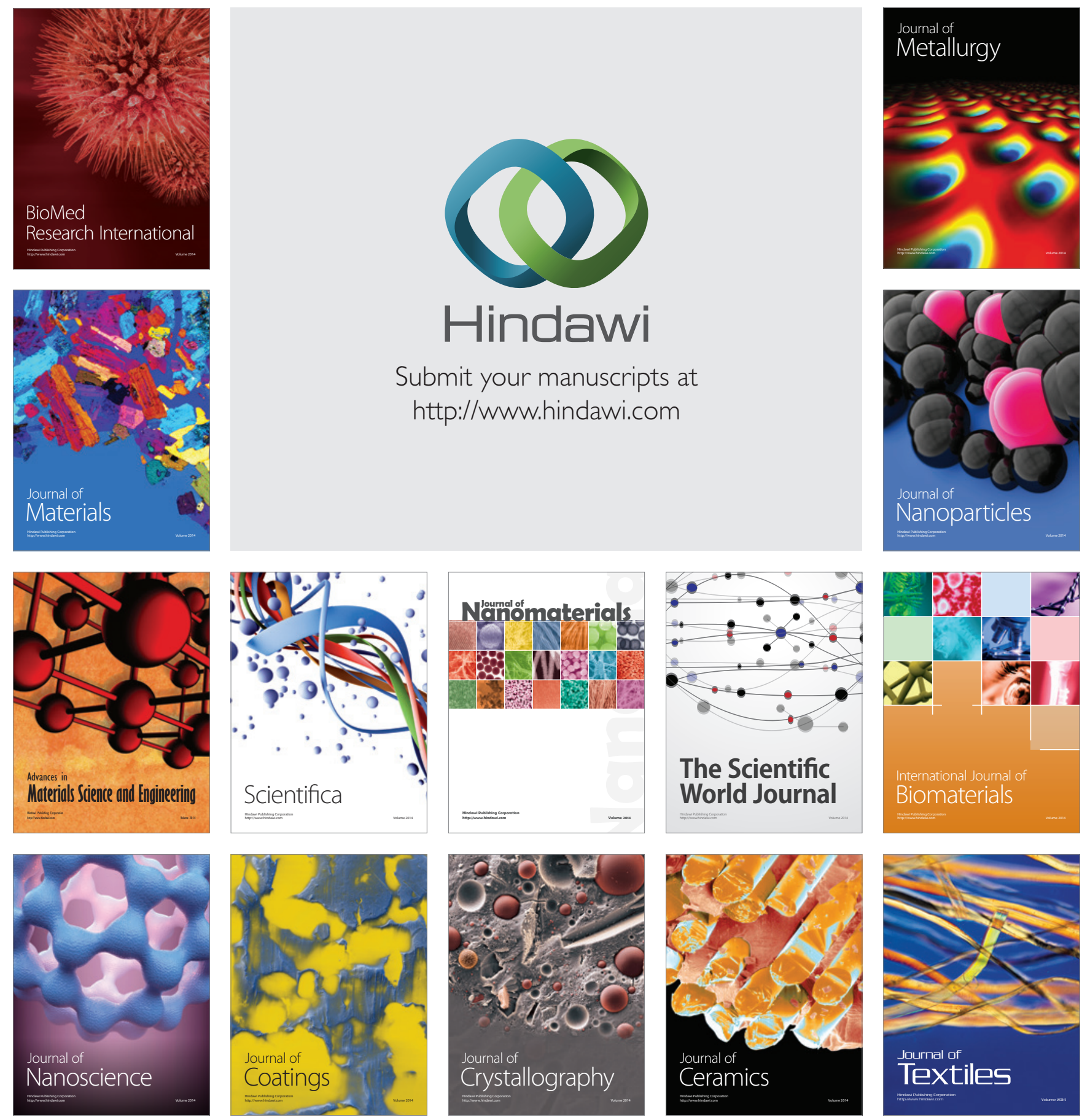